\title{
VALIDAÇÃO DO USO DE n-ALCANOS COMO INDICADORES PARA ESTUDOS NUTRICIONAIS EM VEADOS - \\ CATINGUEIRO (Mazama gouazoubira)
}

\author{
JULIANO BARBOSA
}

Dissertação apresentada à Escola Superior de Agricultura "Luiz de Queiroz", Universidade de São Paulo, para obte nção do título de Mestre em Ecologia de Agroecossistemas.

P I R A C I C A B A

Estado de São Paulo - Brasil

Novembro - 2003 


\title{
VALIDAÇÃO DO USO DE n-ALCANOS COMO INDICADORES PARA ESTUDOS NUTRICIONAIS EM VEADOS - \\ CATINGUEIRO (Mazama gouazoubira)
}

\author{
JULIANO BARBOSA \\ Biólogo
}

Orientador: Prof. Dr. DANTE PAZZANESE DUARTE LANNA

Dissertação apresentada à Escola Superior de Agricultura "Luiz de Queiroz", Universidade de São Paulo, para obtenção do título de Mestre em Ecologia de Agroecossistemas.

P I R A C I C A B A

Estado de São Paulo - Brasil

Novembro - 2003 
Dados Internacionais de Catalogação na Publicação (CIP) DIVISÃO DE BIBLIOTECA E DOCUMENTAÇÃO - ESALQ/ USP

\section{Barbosa, J uliano}

Validação do uso de $n$-Alcanos como indicadores para estudos nutricionais em veados catingueiro (Mazama gouazoubira) / J uliano Barbosa. - - Piracicaba, 2003.

$64 p$

Dissertação (mestrado) - - Escola Superior de Agricultura Luiz de Queiroz, 2003.

Bibliografia.

1. Avaliação nutricional 2. Digestabilidade 3. Hidrocarboreto 4. Veado-campeiro I. Título

CDD 639.9797357

"Permitida a cópia total ou parcial deste documento, desde que citada a fonte - $O$ autor" 
À Deus,

Fonte de sabedoria!

Aos meus pais José Maria e Áurea,

Pelo incentivo e dedicação durante os anos de minha vida.

Ao meu avô,

Por estes anos de convivência, sempre me animando e me apoiando nas horas de desânimo.

À Renata,

Pela paciência e compreensão. 


\section{AGRADECIMENTOS}

Aos Senhores Carlos e Sônia Cantu, pelo carinho e apoio durante esta fase da minha vida.

Ao Professor Dr. Dante Pazzanese D. Lanna pela amizade, orientação e confiança que depositou em mim.

Ao Professor Dr. José Maurício Barbanti Duarte, pelos ensinamentos adquiridos durante o nosso convívio, amizade e exemplo de humildade.

Aos demais Professores do Departamento, pelos ensinamentos e convívio.

Ao querido amigo Dimas, pela paciência e intensa colaboração na execução deste trabalho.

Ao amigo e companheiro Alexandre, pela amizade presente em todos os momentos.

Aos colegas do Laboratório de Nutrição e Crescimento Animal: Andrea, Elaine,

Fernanda, Amanda, Liana, Marina, Adriana, Eduardo, Marco Antônio, Rodrigo, Eric e

Oscar, que durante este tempo sempre me apoiaram e contribuíram para que eu me transformasse neste profissional de hoje.

A técnica de laboratório Tuka e secretária, Ana pela amizade e ajuda.

A CAPES, pela concessão da bolsa de estudos. 


\section{SUMÁRIO}

Página

LISTA DE FIGURAS................................................................ vii

LISTA DE TABELAS............................................................... viii

RESUMO..........................................................................

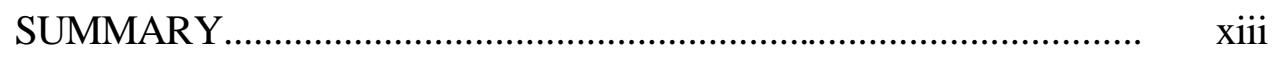

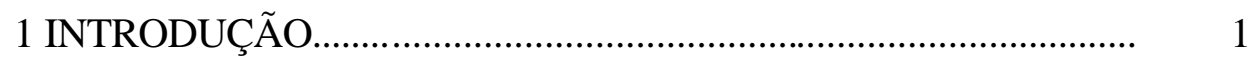

2 REVISÃO DE LITERATURA..................................................... 2

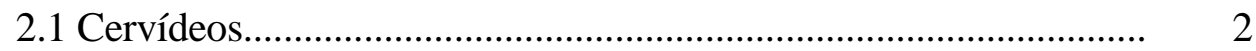

2.1.1 Taxonomia e evolução............................................................ 2

2.2 Classificação dos ruminantes sob o aspecto nutricional.................... 4

2.3 Estudos de digestibilidade ............................................................ 6

2.3.1 Estudos comparativos de digestibilidade através da coleta total de fezes, utilizando espécies de ruminantes pesando mais de $20 \mathrm{~kg} . . . .$.

2.3.2 Estudos comparativos de digestibilidade através da coleta total de fezes, utilizando espécies de ruminantes pesando menos de $20 \mathrm{~kg} . . . \quad 10$

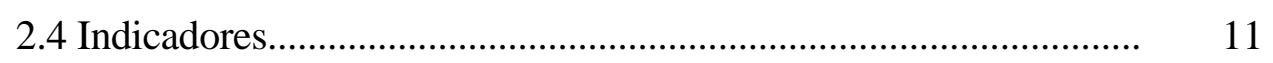

2.4.1 A utilização dos n-alcanos como indicadores fecais em estudos de digestibilidade........................................................................... 12 
2.4.2 A utilização da técnica de duplo alcanos nas estimativas de consumo e digestibilidade.

2.4.3 Utilização dos n-alcanos nas estimativas da composição botânica

3 MATERIAL E MÉTODOS

3.1 Local

3.2 Animais experimentais e dieta.

3.3 Experimento de digestibilidade com coleta total. 21

3.4 Análises bromatológicas. 21

3.5 Cálculos de digestibilidade. 23

3.6 Extração dos nalcanos das amostras de alimentos e fezes.............. 24

3.7 Análises de cromatografia gasosa................................................. 25

3.8 Cálculos de digestibilidade, através do uso de um indicador interno

3.9 Análises estatísticas................................................................ 27

4 RESULTADOS E DISCUSSÃO.................................................... 28

4.1 Consumo de alimento e água............................................................ 28

4.2 Digestibilidade através da coleta total de fezes.............................. 32

4.3 Perfis e concentrações de n-alcanos.................................................. 38

4.4 Digestibilidade estimada através da utilização dos n-alcanos e suas recuperações fecais....................................................................... 40

5 CONCLUSÕES................................................................... 54

REFERÊNCIAS BIBLIOGRÁFICAS.............................................. 55 


\section{LISTA DE FIGURAS}

Página

1 Digestibilidade aparente da fibra em detergente neutro

9

2 Digestibilidade aparente da matéria orgânica.

9

3 Arreio para coleta de fezes.

4 Consumo de matéria seca em 8 veados catingueiro

5 Consumo de água em 8 veados catingueiro

6 Regressão entre as médias de consumo de matéria seca e as médias de ingestão de água em 7 veados catingueiro (Mazama gouazoubira) durante o período de coleta.

7 Recuperações fecais dos nalcanos de cadeia ímpares.

8 Regressão linear entre os nalcanos de cadeia ímpares, e as médias de suas recuperações fecais em 8 veados catingueiro (Mazama gouazoubira). 


\section{LISTA DE TABELAS}

Página

1 Valores bromatológicos da dieta oferecida aos animais durante o período de coleta (valores em $100 \%$ de matéria seca).

2 Níveis de garantia do premix vitamínico mineral por $\mathrm{kg}$

3 Médias do consumo de matéria seca e água obtidas durante o período de coleta.

4 Consumo e digestibilidade dos nutrientes de oito veados catingueiro (Mazama gouazoubira durante o período de coleta.

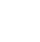

5 Coeficientes de digestibilidade em espécies pesando menos de 20kg, recebendo dietas com diferentes concentrações de FDN.

6 Coeficientes de digestibilidade em espécies pesando mais de $20 \mathrm{~kg}$, recebendo dietas com diferentes concentrações de FDN 
7 Concentração dos nalcanos (mg/kg MS) nos ingredientes utilizados na dieta.

8 Consumo, digestibilidade observada e estimada para matéria seca e matéria orgânica utilizando os n-alcanos $C_{29}, C_{31}$ e $C_{33}$ em veados catingueiros $(\mathrm{n}=8)$.

9 Consumo, digestibilidade observada e estimada para o nitrogênio e o extrato etéreo utilizando os $n$-alcanos $C_{29}, C_{31}$ e $C_{33}$ em veados catingueiros $(\mathrm{n}=8)$.

10 Consumo, digestibilidade observada e estimada para a energia e o FDN utilizando os n-alcanos $\mathrm{C}_{29}, \mathrm{C}_{31}$ e $\mathrm{C}_{33}$ em veados catingueiros $(n=8)$ 
11 Equações de regressão entre os coeficientes de digestibilidade estimados com os n-alcanos $\mathrm{C}_{31}$ e $\mathrm{C}_{33}$ e os coeficientes de digestibilidade observados

12 Consumo (g), produção fecal (g) e recuperação fecal (\%) dos nalcanos $\mathrm{C}_{29}, \mathrm{C}_{31}$ e $\mathrm{C}_{33}$ com veados catingueiros.

13 Consumo, digestibilidade observada e estimada para matéria seca e matéria orgânica utilizando os n-alcanos $C_{31}$ e $C_{33}$ ajustados para

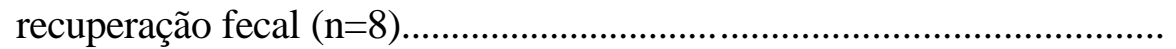

14 Consumo, digestibilidade observada e estimada para o nitrogênio e o extrato etéreo utilizando os n-alcanos $\mathrm{C}_{31}$ e $\mathrm{C}_{33}$ ajustados para recuperação fecal $(\mathrm{n}=8)$.

15 Consumo, digestibilidade observada e estimada para a energia e o FDN, utilizando os n-alcanos $\mathrm{C}_{31}$ e $\mathrm{C}_{33}$ ajustados para recuperação fecal $(n=8)$ 


\title{
VALIDAÇÃO DO USO DE n-ALCANOS COMO INDICADORES PARA ESTUDOS NUTRICIONAIS EM VEADOS - CATINGUEIRO (Mazama gouazoubira)
}

\author{
Autor: JULIANO BARBOSA
}

Orientador: Prof. Dr. DANTE PAZZANESE DUARTE LANNA

\section{RESUMO}

Determinações do consumo e da digestibilidade, através do método de coleta total de fezes, foram realizadas em 8 veados-catingueiros (Mazama gouazoubira) recebendo uma dieta peletizada composta por 63,9\% de feno de alfafa, 16,9\% de amido de milho, 14,7\% de levedura (Saccharomyces cerevisiae), 2,5\% de melaço, 1,5\% de um premix vitamínico-mineral e $0,5 \%$ de cloreto de sódio em base seca. As estimativas dos coeficientes de digestibilidade foram determinadas paralelamente através do uso de indicador fecal (n-alcanos) com o intuito de validar a metodologia para esses pequenos ruminantes. $\mathrm{O}$ consumo médio de matéria seca e água durante o período de coleta foram: $24 \mathrm{~g} \pm 2,5$ e $67 \mathrm{~mL} \pm 11,5$ por quilo de peso vivo (PV), sendo que os animais não apresentaram perdas de peso durante o período experimental. Quando expresso em peso metabólico $\left(\mathrm{PV}^{0,75}\right)$, os animais consumiram em média 48g \pm 5,2 de matéria seca e 136,4 $\mathrm{mL} \pm 23,8$ de água. $\mathrm{O}$ consumo de energia digestível foi em média $1.089 \mathrm{kcal} /$ dia. As 
médias dos coeficientes de digestibilidade aparente obtidas através da coleta otal de fezes, foram de $61,6 \% \pm 1,7$ para matéria seca, 63,9\% $\pm 1,6$ matéria orgânica, 69,7\% \pm 3,4 nitrogênio, 31,7\% $\pm 3,7$ fibra em detergente neutro, 45,2 $\pm 2,4$ celulose e 18,8 \pm 5,6 para a lignina. Os coeficientes de digestibilidade estimados para as diferentes frações através da utilização dos n-alcanos $\mathrm{C}_{31}$ e $\mathrm{C}_{33}$ se mostraram precisos e acurados em relação aos coeficientes de digestibilidade observados por coleta total quando as recuperações fecais foram incluídas nos cálculos de digestibilidade $(\mathrm{P}>0,05)$. Consistente com valores obtidos em ovinos, as recuperações fecais dos n-alcanos de cadeia ímpares aumentaram com o aumento do número de carbonos da cadeia de hidrocarboneto sendo que estes valores poderão ser utilizados em futuros estudos onde se deseja determinar a composição botânica da dieta dos cervídeos. 


\title{
VALIDATION OF THE USE OF n-ALKANES AS MARKERS FOR NUTRITIONAL TRIALS WITH GREY BROCKET DEER
}

\author{
(Mazama gouazoubira)
}

Author: JULIANO BARBOSA

Adviser: Prof. Dr. DANTE PAZZANESE DUARTE LANNA

\begin{abstract}
Feed intake and digestibility estimates were determined by the total fecal collection method of 8 deer (Mazama gouazoubira) receiving a pelleted diet of $63.9 \%$ alfalfa hay, $16.9 \%$ corn starch, $14.7 \%$ yeast (Saccharomyces cerevisiae), $2.5 \%$ mollasses, $1.5 \%$ mineral-vitamin mix, and $0.5 \% \mathrm{NaCl}$ on $\mathrm{DM}$ basis. n-alkane tracer method was used in parallel with total fecal collection to validate its application on wild small ruminants. The mean DM feed intake and water intake during the collection period were $24 \mathrm{~g} \pm 2.5$ and $67 \mathrm{~mL} \pm 11.5$ per $\mathrm{kg} \mathrm{BW}$, and the animals did not present weight losses during the experimental period. When these values were expressed on $\mathrm{kg}$ of metabolic live weight, the animals consumed $48 \mathrm{~g} \pm 5.2$ of $\mathrm{DM}$ and $136.4 \mathrm{~mL} \pm 23.8$ of water. Digestible energy intake was estimated at $1,089 \mathrm{kcal} /$ day. The mean coefficients of apparent digestibility observed by total fecal collection for dry matter was $61.6 \% \pm$ 1.7 ; organic matter $63.9 \% \pm 1.6$, nitrogen $69.7 \% \pm 3.4$, neutral detergent fiber $31.7 \% \pm$
\end{abstract}


3.7, cellulose $45.2 \% \pm 2.4$, and lignin $18.8 \% \pm 5.6$. The digestibility coefficients estimated for the different fractions by the ralkanes $C_{31}$ and $C_{33}$ were accurate when compared to those observed by the total fecal collection method when feces recovery was included on digestibility calculations $(\mathrm{P}>0.05)$. Consistent with values obtained in sheep, the fecal recoveries of the odd chain ralkanes was greater with the increase of the number of carbons of the chain of hydrocarbon and these values can be used in future studies to determine the botanical composition of the deer's diet. 


\section{INTRODUÇÃO}

Embora menos numerosos do que os ruminantes domésticos, os ruminantes selvagens também são importantes para os humanos e para a manutenção da funcionalidade de diferentes sistemas. Algumas espécies de cervídeos, como o veado de cauda branca (Odocoileus virginianus), coexistem muito bem com humanos, mesmo em áreas suburbanas, e há provavelmente mais indivíduos desta espécie no leste da América do Norte atualmente, do que em todos os tempos. Esta espécie se adapta muito bem às transformações do ambiente causadas pelo homem, usando as áreas agrícolas como fonte de alimento e o mosaico destas áreas como reservas de matas para proteção. Porém, outras espécies de cervídeos vêm sofrendo sérias ameaças de serem futuramente extintas, devido principalmente às alterações ambientais e à caça indiscriminada. Essas espécies não se adaptam à ocupação humana e à destruição de florestas, exigindo proteção efetiva para não se extinguirem (Van Soest, 1994).

Devido às alterações ambientais, estes animais pouco adaptados à presença humana acabam sendo obrigados a se deslocarem para áreas impróprias ou são capturados e levados para zoológicos ou parques onde muitas vezes acabam morrendo devido à falta de conhecimento sobre suas exigências nutricionais. Esta escassez de informações, principalmente em relação aos cervídeos sul-americanos, fez com que este projeto tivesse como objetivo primordial estudar alguns aspectos nutricionais como consumo e digestibilidade desses animais em cativeiro, recebendo dietas não condizentes com as consumidas em seu habitat, assim como validar uma metodologia capaz de estimar com acurácia alguns parâmetros nutricionais que podem ser utilizados como ferramentas importantes nas tomadas de decisões referentes ao manejo e a conservação dessas espécies em diferentes ambientes. 


\section{REVISÃO DE LITERATURA}

\subsection{Cervídeos}

\subsubsection{Taxonomia e evolução}

Os cervídeos são animais da ordem Artiodactyla, que se caracterizam pela presença de cascos, onde apenas dois dos quatros dedos de cada extremidade apóiam ao solo. Na maioria dos cervídeos, os machos apresentam chifres, com exceção dos animais do gênero Moschus e da espécie Hydropotes inermis. Já no caribu (Rangifer tarandus), os chifres são encontrados tanto nos machos quanto nas fêmeas. Os chifres são formados a partir do osso frontal, sendo estes recobertos por um "velame" durante sua fase de crescimento, cuja função é depositar cálcio na matriz óssea do chifre durante o período de crescimento. Geralmente os chifres começam a aparecer após o primeiro ano de vida do animal. Em algumas espécies como o cervo-do-pantanal (Blastocerus dichotomus) a medida que os chifres crescem estes se ramificam, já outras espécies do gênero Mazama, não apresentam ramificações em seus pequenos chifres (Duarte, 1997).

Segundo esse autor, a maioria das espécies sul-americanas, apresenta apenas um filhote por cria, sendo raros os casos de gêmeos. Descreve ainda, que enquanto a primeira muda de pêlo não ocorre, os filhotes apresentam pintas brancas no dorso e nas laterais do corpo, com exceção do cervo-do-pantanal e do huemul (Gênero Hippocamelus).

Outra característica dos cervídeos é a grande quantidade de glândulas odoríferas, que têm por objetivo ajudar na comunicação dos indivíduos de uma mesma espécie, 
sendo as principais: metatarsais, tarsais, pré-orbitais, nasais e interdigitais (Duarte, 1997).

Por pertencerem ao grupo dos ruminantes, os cervídeos possuem seu estômago dividido em quatro compartimentos: rúmen, retículo, omaso e abomaso. O alimento ingerido é primeiramente mastigado, e exposto à ação de enzimas digestivas presentes na saliva do animal, dando início ao processo de digestão. Em seguida, o alimento passa pelo esôfago em direção ao retículo e rúmen, os quais apresentam uma população de microrganismos anaeróbicos, responsáveis pela digestão de carboidratos complexos e outros compostos através da fermentação. Os ácidos acético, propiônico e butírico são os principais ácidos graxos voláteis produzidos pela fermentação microbiana, sendo absorvidos na parede do rúmen e utilizados pelos animais como fontes de energia. A ruminação permite que as partículas maiores do alimento sejam remastigadas e devolvidas ao rúmen, acompanhadas por uma nova fração de saliva, sendo esta a responsável pela manutenção do $\mathrm{pH}$ ruminal. Quando as partículas do alimento são reduzidas o suficiente para passarem pelo orifício retículo-omasal, seguem até o abomaso, sendo este o principal local de liberação enzimática (Church, 1993).

Os cervídeos são os ruminantes selvagens mais distribuídos no mundo, sendo encontrados em quase todos os continentes exceto na Antártida (Van Soest, 1994). No mundo existem 17 gêneros e 45 espécies de cervídeos distribuídos nas Américas, Europa, Ásia e África (Walker, 1991).

A origem dos cervídeos continua um tanto obscura, porém acredita-se que a radiação adaptativa dos cervídeos provavelmente iniciou-se na Eurásia a aproximadamente 20 milhões de anos, com os gêneros Dicrocerus e Procervulus. Durante o Pleistoceno, os cervídeos iniciaram uma radiação adaptativa à América do sul, ocupando diferentes nichos (Eisenberg, 1984). Os animais do gênero Mazama ocuparam florestas densas, de maneira similar aos "Duikers" da África e aos "Muntjacs" da Ásia. O gênero Mazama está dividido em 7 espécies: Mazama americana (Erxleben, 1777), Mazama gouazoubira (Fischer, 1814), Mazama nana (Hensel, 1872), Mazama rufina (Bourcier \& Pucheran, 1852), Mazama chunyi (Hershkovits, 1959), Mazama bricennii (Thomas, 1908) e Mazama bororo (Duarte, 1992) e o processo exato de seleção para o 
pequeno tamanho corporal das espécies não é bem compreendido. Porém, a adaptação desses animais às florestas densas pode ter favorecido sua pequena estatura (Eisenberg, 1984).

\subsection{Classificação dos ruminantes sob o aspecto nutricional}

Sabe-se que os ruminantes selvagens ocupam uma grande diversidade de nichos no planeta. Embora eles consumam uma ampla variedade de alimentos com diferentes características físico-químicas, os nutricionistas classificam os ruminantes em três principais categorias: os selecionadores de alimentos de alta digestibilidade ou "browsers", os consumidores de alimentos de alta fibra ou "grazers", e os intermediários. Este último apresenta comportamento inerente às espécies "browsers" e "grazers" dependendo da disponibilidade de alimentos. Esta classificação foi resultado do trabalho pioneiro de Hofmann em 1973, que examinou a seleção de alimentos desses grupos, em relação a sua anatomia digestiva, e concluiu que as adaptações gerais do sistema digestivo correspondem ao papel ecológico do animal. Essas hipóteses determinaram que os ruminantes "grazers" são melhor adaptados a consumir plantas de baixa digestibilidade ricas em fibra, em relação a ruminantes "browsers" por apresentarem grandes rúmens, estruturalmente adaptados, a reter a passagem dos alimentos para o baixo-trato. Ao contrário, animais "browsers" apresentam rúmen e omaso menor em relação aos "grazers" e grandes glândulas salivares, sendo estas as responsáveis pela produção de grandes quantidades de saliva, auxiliando na manutenção do $\mathrm{pH}$ ruminal. Segundo esse mesmo autor, mais de $40 \%$ das espécies de ruminantes existentes, são considerados selecionadores de alimentos e são dotados com um sistema digestivo pouco adaptado a otimizar a digestão de plantas fibrosas, sendo adaptados a processar e digerir forragens de alta digestibilidade, ricas em conteúdo celular.

Hofmann (1973), ainda sugeriu que esses pequenos ruminantes "browsers" selecionam alimentos concentrados como grãos ou frutas que passam diretamente pelo rúmen, compensando a baixa suplementação de energia vinda da produção de ácidos graxos voláteis. Este comportamento permite que pequenos ruminantes evitem perdas de 
energia, oriundas da fermentação microbiana, produção de metano, calor e partes indigestíveis de microrganismos.

$\mathrm{Na}$ tentativa de classificar os ungulados em relação às suas estratégias de alimentação, Hofmann (1988) incluiu todos os ungulados que habitam as florestas tropicais como sendo parte do grupo dos selecionadores ou "browsers". Esta cate goria inclui animais que se alimentam de arbustos, folhas de dicotiledôneas e frutas. Com relação a essa classificação, Bodmer (1990) determinou que os ungulados frugívoros apresentam muitas diferenças ecológicas em relação aos "browsers" e devem ser representados por um grupo independente. Segundo este autor, os ungulados exclusivamente frugívoros, são restritos a florestas tropicais e apresentam, freqüentemente, pequenos tamanhos corporais. Por outro lado, os "browsers", apresentam uma ampla variedade de tamanho corporal, como também são encontrados em quase todos os tipos de ambientes. Em 1989, Bodmer observou que o veadocatingueiro (Mazama gouazoubira) e o veado-mateiro (Mazama americana), provenientes da Amazônia, são animais frugívoros, pois consomem grandes proporções de frutas em relação às folhas. As amostras de rúmen dos veados catingueiros coletadas nesse experimento apresentaram $87 \%$ de frutas sendo que em veados mateiros essa proporção foi de $81 \%$. As sementes de Euterpe sp. e Iriartea sp. foram os alimentos mais consumidos pelos veados, sendo estas encontradas em $80 \%$ dos veadoscatingueiros e em $59 \%$ dos veados mateiros amostrados.

As interpretações ecológicas e nutricionais de Hofmann influenciaram por muito tempo a maneira pela qual os ecologistas e nutricionistas enxergavam a evolução dos ruminantes e seus comportamentos, assim como a organização e composição de comunidades de herbívoros (Owen-Smith, 1991). Entretanto, com o intuito de testar as idéias de Hofmann, Gordon \& Illius (1994) sugeriram que o tamanho corporal é o mais importante fator que influencia o comportamento alimentar e a fisiologia digestiva em espécies de ruminantes. Estes autores compararam a média do tempo de retenção da digesta entre espécies de ruminantes africanos, dentre eles oito "browsers", sete intermediários e onze "grazers" e, determinaram que 99,6\% da variação foi explicada por um modelo no qual se utilizava a massa corporal dos animais e o tipo de alimento. 
Da mesma forma, Robbins et al. (1995) argumentaram que a taxa de passagem da digesta do rúmen e a digestão da fibra estão ligados ao peso corporal.

Analisando a morfologia do estômago de 28 espécies de Artiodactyla com diferentes classificações nutricionais, através de análises multivariadas e correções filogenéticas, Barbería et al. (2001) observaram que controlando o efeito da massa corporal e da filogenia sobre a morfologia do estômago, não encontraram grupos significativos de espécies em relação ao estilo de alimentação.

\subsection{Estudos de digestibilidade}

Os estudos comparativos de digestibilidade podem ser utilizados como uma importante ferramenta, auxiliando na classificação nutricional dos ruminantes. Estes experimentos são conduzidos com várias espécies com o intuito de comparar seus coeficientes de digestão e demonstrar a superioridade de uma espécie sobre outra, ou para demonstrar iguais habilidades digestivas. Porém, sabe-se que valores de digestibilidade semelhantes entre duas espécies não necessariamente indicam idênticas capacidades digestivas e metabólicas (Van Soest, 1994).

A análise química de um determinado alimento é o ponto inicial para se determinar seu valor nutritivo, porém sabe-se que nem todo nutriente ingerido pelo animal pode ser absorvido e utilizado pelo mesmo. A primeira consideração a ser tomada quando se pretende determinar o valor nutricional de um alimento, é determinar sua digestibilidade, uma vez que os nutrientes indigestíveis não podem ser utilizados pelo animal (Maynard \& Loosli, 1969).

O primeiro experimento de digestibilidade foi conduzido tão logo os métodos químicos usualmente aplicados foram desenvolvidos. De fato, alguns destes métodos foram desenvolvidos pelos mesmos pesquisadores que conduziram alguns dos primeiros experimentos de digestibilidade na estação experimental de Weende (Schneider \& Flatt, 1975). Segundo estes mesmos autores, o primeiro trabalho sobre perdas de nutrientes nas fezes, com o intuito de validar os valores de energia dos alimentos, em termos de nutrientes digestíveis totais, iniciou-se antes de 1860. 
O procedimento básico envolvido em um experimento de digestibilidade com coleta total, consiste em se medir a quantidade de um determinado nutriente consumido e a quantidade deste nutriente excretado nas fezes durante um período experimental. Tendo a quantidade e a composição química de um alimento consumido e das fezes, a digestibilidade deste e suas várias frações podem ser computadas (Schneider \& Flatt, 1975).

Os valores de digestibilidade podem ser expressos como digestibilidade real ou aparente. Sabe-se, porém, que nas fezes encontram-se não apenas as frações da dieta que não foram digeridas, mas também produtos metabólicos incluindo bactérias e perdas endógenas provenientes do metabolismo animal. Conseqüentemente, a digestibilidade aparente pode ser considerada como um balanço entre o alimento consumido menos as fezes excretadas. Já a digestibilidade real pode ser considerada como um balanço entre a dieta consumida e seus resíduos que escaparam da digestão e saíram nas fezes (Van Soest, 1994). Segundo este mesmo autor, resíduos de alimentos que passam pelo trato digestivo sem serem digeridos pelo animal são difíceis de serem computados, porque a matéria metabólica pode ser gerada através da fermentação desses resíduos.

\subsubsection{Estudos comparativos de digestibilidade através da coleta total de fezes, utilizando espécies de ruminantes pesando mais de $20 \mathrm{~kg}$}

Em um estudo comparativo de digestibilidade envolvendo três espécies de ruminantes com diferentes classificações nutricionais, segundo Hofmann (1989), dentre eles o bisão (Bison bison) um animal que consome grandes quantidades de fibra, o cervo-nobre (Cervus elaphus) um intermediário e o veado-de-cauda-branca (Odocoileus virginianus), um selecionador de alimentos de fácil degradabilidade, Galbraith et al. (1998), testaram dietas a base de alfafa peletizada, e não encontraram diferenças na capacidade, entre as espécies, em digerir a matéria seca, matéria orgânica, energia, nitrogênio, FDN ou FDA da dieta.

Do mesmo modo, Semiadi et al. (1994), não encontraram diferenças nos coeficientes de digestibilidade entre o cervo-nobre e o cervo-sambar (Cervus unicolor) 
quando alimentados com feno de alfafa, durante diferentes estações do ano (verão e inverno). Observaram ainda que o aumento de consumo dos cervos-nobre durante o verão, não interferiu nos seus coeficientes de digestibilidade. Segundo Domingue et al. (1991), esses valores constantes de digestibilidade apresentados entre as estações pelo cervo-nobre, são devido a uma redução na taxa de renovação fracional do rúmen durante o verão, levando a um aumento do volume do rúmen, e ao mesmo tempo aumentando o tempo de exposição da dieta à ação dos microrganismos. Talvez essas estratégias de alimentação, possam explicar os maiores coeficientes de digestibilidade obtidos pelo cervo-nobre em relação ao cervo-sambar para o FDN $(\mathrm{P}<0,10)$ e para a celulose $(\mathrm{P}<0,05)$ durante o experimento de Howse et al. (1995). Já para matéria seca, matéria orgânica, energia, FDA e hemicelulose os autores não identificaram diferenças nos coeficientes de digestibilidade.

Em um estudo de digestão conduzido por Huston et al. (1986), com o objetivo de comparar a digestibilidade da matéria seca em bovinos, ovinos, caprinos e cervídeos, recebendo uma dieta peletizada com aproximadamente $60 \%$ de volumoso (casca de algodão e feno de alfafa), observaram que a digestibilidade da matéria seca foi significativamente maior nos bovinos $(64,3 \%)$ em relação aos cervídeos $(55,7 \%)$. Já os ovinos e caprinos, apresentaram valores intermediários de digestibilidade com nenhuma diferença significativa com os valores extremos. Comentaram ainda, que dos quatro cervídeos que iniciaram o experimento, dois foram removidos pela dificuldade de se adequarem ao confinamento, reduzindo o poder do teste de hipóteses.

Com relação à matéria orgânica e a fibra em detergente neutro, pode-se observar através da Figura 1 e 2, as diferenças nos coeficientes de digestibilidade entre cervídeos, caprinos e ovinos recebendo três dietas em quantidades controladas com diferentes proporções de volumoso:concentrado (10:90, 50:50 e 90:10) obtidos durante o estudo de Ramanzin et al. (1997). 


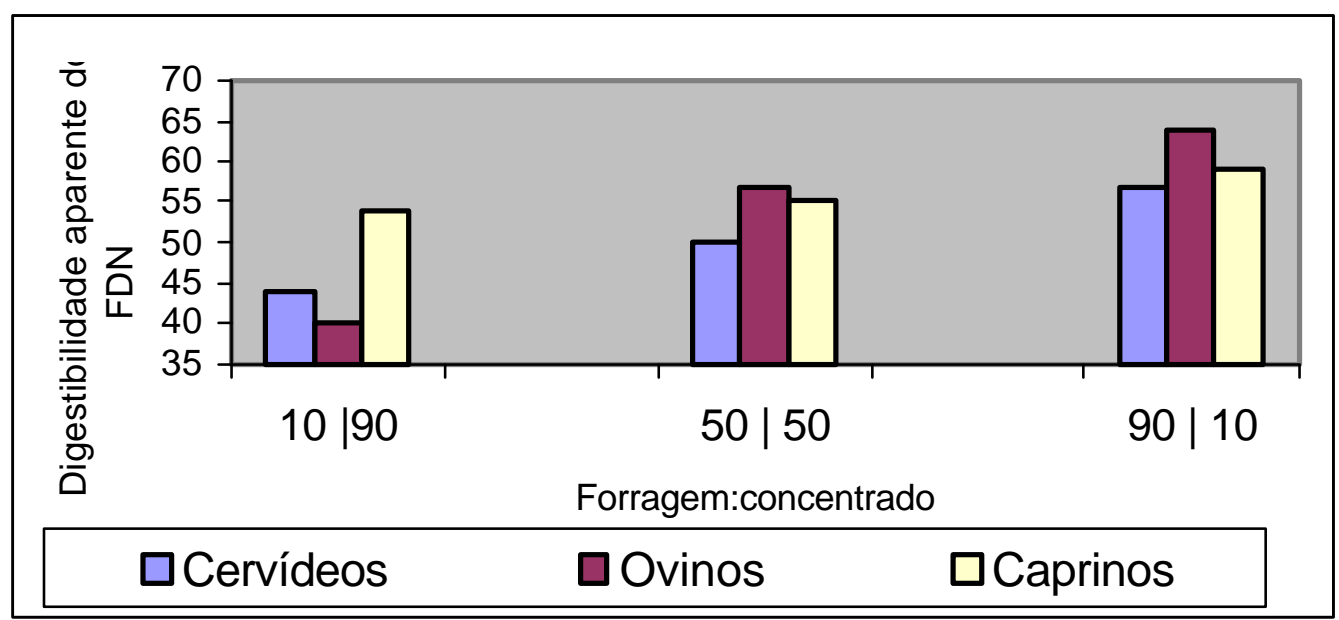

Figura 1- Digestibilidade aparente da matéria orgânica

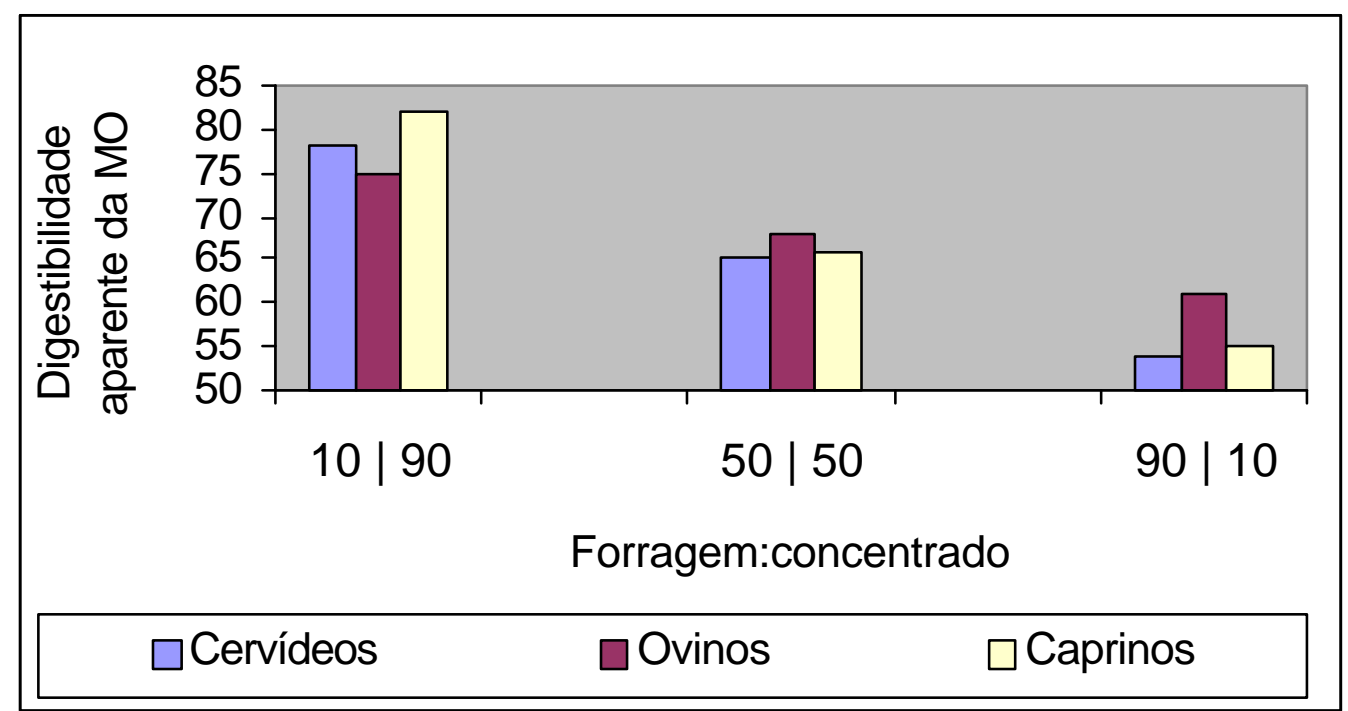

Figura 2 - Digestibilidade aparente da fibra em detergente neutro

Durante esse estudo, os ovinos apresentaram as maiores taxas de ingestão, digestibilidade aparente e o maior tempo de retenção da digesta, no rúmen, quando alimentados com a dieta rica em forragem, já os caprinos tiveram uma tendência a 
selecionar os componentes da dieta, e apresentaram menores taxas de ingestão dos alimentos em relação aos ovinos e uma menor digestibilidade aparente, quando alimentados com a dieta rica em forragem. Os cervídeos tiveram valores de digestibilidade aparente da dieta rica em forragem menores do que os caprinos, e apresentaram tempos de retenção da digesta, no rúmen, menores do que os caprinos e ovinos sob todas as dietas, e uma ingestão similar a dos ovinos com nenhuma evidência de seleção.

\subsubsection{Estudos comparativos de digestibilidade através da coleta total de fezes, utilizando espécies de ruminantes pesando menos de $20 \mathrm{~kg}$}

Observando o comportamento ingestivo, tempo de ruminação, digestibilidade e a taxa de passagem de três diferentes dietas: figo (Ficus carica); alfafa (Medicago sativa) e folhas de salgueiro (Salix lasiandra) com variação de 10 a 50\% do FDN em "blue duikers" (Cephalophus monticola), Wenninger \& Shipley (2000) concluíram que o comportamento ingestivo e o tempo de ruminação foram mais rápidos quando estes animais se alimentaram com dietas a base de figo em relação à alfafa e as folhas de salgueiro e, que a digestibilidade da matéria seca, da energia, do FDN e da proteína foram maiores com o figo em relação às outras dietas. Embora as digestibilidades da matéria seca, energia, FDN e da proteína foram maiores quando os animais consumiram figo, a ingestão de energia digestível diária foi maior com as folhas de salgueiro e alfafa, devido aos animais terem consumido proporcionalmente mais dessas forragens. Os "blue duikers" foram capazes de compensar a baixa digestibilidade da matéria seca e do FDN das folhas de salgueiro, ingerindo $50 \%$ a mais de matéria seca, e ruminando e mastigando sete vezes mais do que quando eram alimentados com dietas de baixa fibra como o figo. De fato os "blue duikers" digeriram as folhas de salgueiro, com $49 \%$ de FDN, melhor do que o esperado em relação ao seu tamanho corporal. Alcançando valores de digestibilidade de energia de $60 \%$ e $51 \%$ para FDN, os "blue duikers" mostraram ser capazes de competir na digestão da fibra com grandes herbívoros recebendo dietas entre 37 e $53 \%$ de FDN. 
Em outro estudo, Conklin- Brittain \& Dierenfeld (1996) compararam a ingestão e a digestibilidade em uma espécie "browser", o pudu (Pudu pudu) e três espécies de frugívoros, dentre elas o veado mateiro, o "bay duiker" (Cephalophus dorsalis) e o "Maxwell's duiker" (C. maxwellii) e concluíram que os maiores animais não tiveram uma maior digestibilidade da fibra em relação às espécies menores. Segundo ConklinBrittain \& Dierenfeld (1994), o veado-camundongo (Tragulus napu) digeriu melhor uma dieta com 25\% de FDN, quando comparado a ovinos recebendo a mesma dieta. Estes resultados são similares aos encontrados com pequenos fermentadores do trato digestivo posterior e em não ruminantes com fermentação anterior no trato digestivo, mostrando que os pequenos herbívoros podem sobreviver com dietas de alta fibra (acima de 80\%), aumentando a ingestão e a capacidade do intestino (Hammond \& Wunder, 1991; Cork, 1994). Esses pequenos ruminantes podem também melhorar a sua digestibilidade triturando as partículas de alimento eficientemente, expondo o conteúdo celular mais rápido à fermentação (Conklin \& Dierenfeld, 1994). Além disso, pequenos "browsers" têm relativamente um maior trato digestivo posterior do que grandes herbívoros, aumentando desta forma a absorção dos nutrientes de modo a atingir suas exigências (Hofmann, 1989).

\subsection{Indicadores}

Para se compreender a relação entre os herbívoros e seus habitats, existe uma necessidade de se obter informações quantitativas sobre seus hábitos alimentares, isto é, o que eles comem, quanto eles comem e qual a qualidade nutricional de suas dietas.

Determinações acuradas da composição botânica, consumo e digestibilidade da dieta em herbívoros selvagens, não são fáceis de serem obtidas, principalmente quando se deseja intervir o mínimo possível no comportamento natural dos animais. Porém, as fezes desses animais, as quais podem ser facilmente coletadas, são constituídas principalmente por compostos indigestíve is, podendo estes, serem explorados como indicadores para se determinar a digestibilidade da dieta, o consumo e a composição botânica. Dentre estes compostos, os hidrocarbonetos alifáticos saturados (n-alcanos) 
presentes na cera das plantas, apresentam um grande potencial para serem utilizados como indicadores, pois desde que estejam presentes em concentrações significativas nas plantas, são relativamente inertes, pouco digestíveis e podem ser facilmente analisados por cromatografia gasosa (Dove \& Mayes, 1991).

$\mathrm{Na}$ cera das plantas, os n-alcanos com número ímpar de átomos de carbono, predominam sobre os de número par, variando o comprimento da cadeia entre $C_{25}$ a $C_{35}$ (Hawke, 1973). Segundo Tulloch (1976) os n-alcanos são encontrados em todas as ceras, variando em suas quantidades, sendo que os principais contêm números ímpares de átomos de carbono variando de $\mathrm{C}_{21}$ a $\mathrm{C}_{37}$, sendo o $\mathrm{C}_{31}$ o que aparece em maior concentração, seguido do $\mathrm{C}_{29}$.

Mais recentemente, Dove et al. (1996) também obtiveram resultados semelhantes com os trabalhos citados anteriormente, onde os n-alcanos com número ímpar de átomos de carbono foram predominantes na cera cuticular das plantas em estudo, principalmente o $\mathrm{C}_{27}, \mathrm{C}_{29}, \mathrm{C}_{31}$ e $\mathrm{C}_{33}$. Os cálculos dos coeficientes de similaridade indicaram que a maior similaridade nos padrões das concentrações dos n-alcanos ocorreu entre partes de plantas dentro de uma espécie ou entre as mesmas partes das plantas em espécies intimamente relacionadas.

\subsubsection{A utilização dos n-alcanos como indicadores fecais em estudos de digestibilidade}

Dentre as diferentes substâncias encontradas nas ceras das plantas, Oró et al. (1965) comentaram sobre a indigestibilidade dos hidrocarbonetos alifáticos saturados promovendo uma similaridade entre os padrões destes hidrocarbonetos extraídos das fezes de bovinos com os padrões da forragem consumida (Medicago arabica). Observaram também, que os animais selecionaram a dieta em favor da fração folha, pela grande semelhança entre o perfil dos hidrocarbonetos das folhas e das fezes. Mesmo tendo observado tal similaridade, foi apenas em 1984 que Mayes \& Lamb constataram a possibilidade de utilização desses hidrocarbonetos, também conhecidos como n-alcanos, como indicadores para determinar a digestibilidade das forragens. Neste trabalho, os 
autores perceberam um aumento na recuperação fecal, conforme aumentava o comprimento da cadeia carbonada dos nalcanos, sendo que o ralcano $\mathrm{C}_{35}$ apresentou valores de recuperação fecal próximos a 98\%.

A estimativa da digestibilidade utilizando um indicador se baseia no fato de que, durante a passagem do alimento pelo trato-digestivo, uma fração da dieta sofre digestão e absorção. Conseqüentemente, as frações mais indigestíveis tornamse mais concentradas nas fezes do que na dieta consumida. Deste modo, amostras representativas da dieta e das fezes podem ser utilizadas para se estimar a digestibilidade:

$$
\text { Digestibilidade }=1-\frac{\text { Concentração do indicador na dieta }}{\text { Concentração do indicador nas fezes }}
$$

Subseqüente ao trabalho de Mayes \& Lamb (1984), vários trabalhos foram realizados a fim de se testar a adequabilidade dos n-alcanos como indicadores de digestibilidade.

Piasentier et al. (1989) utilizaram amostras de fezes e alimentos oriundos de 8 experimentos de digestibilidade e observaram que a recuperação fecal média do n-alcano $\mathrm{C}_{33}$ foi de $83,4 \%$, de modo que os valores de digestibilidade observados foram sempre subestimados. Porém, através da utilização dos nalcanos $\mathrm{C}_{31}$ e $\mathrm{C}_{33}$ a correlação entre a digestibilidade observada através da coleta total das fezes, com a estimada pelos indicadores foi de 0,80 e 0,84 , respectivamente.

Outro trabalho com o objetivo de investigar a utilização do nalcano $\mathrm{C}_{35}$ como indicador interno para determinação da digestibilidade, foi desenvolvido por Oliveira et al. (1997). Estes autores utilizaram amostras de fezes e fenos de experimentos de digestibilidades convencionais realizados entre os anos de 1978 a 1982 e concluíram que o $\mathrm{C}_{35}$ subestimou as digestibilidades da matéria seca e orgânica apresentando diferenças médias em relação aos valores in vivo de $4,68( \pm 0,69)$ e $4,43( \pm 0,85)$ unidades percentuais, respectivamente. Porém, os coeficientes de correlação da matéria seca e 
matéria orgânica obtidos foram considerados bons entre as medidas com indicador e in vivo.

Embora os nalcanos possam ser analisados com alta acurácia e precisão, eles não são completamente recuperados nas fezes, e por isso acabam subestimando os coeficientes de digestibilidade. Corrigindo suas recuperações fecais podem ser utilizados com segurança nas estimativas de digestibilidade.

Mais recentemente, estudos comparativos como o de Sandberg (2000) e Clauss et al. (2001) testaram os n-alcanos com outros indicadores, e observaram que estes forneceram as estimativas mais precisas da digestibilidade.

\subsubsection{A utilização da técnica de duplo alcanos nas estimativas de consumo e digestibilidade}

Em herbívoros sob condições de pastejo, o consumo pode ser determinado se a digestibilidade da dieta e a produção fecal forem determinadas. Neste caso:

$$
\text { Consumo }=\frac{\text { Produção fecal }}{(1-\text { Digestibilidade da dieta })}
$$

A digestibilidade pode ser determinada usando o método descrito anteriormente, já a produção fecal pode ser medida utilizando arreios de coleta como pode ser observado na Figura 3. Porém, é mais conveniente e causa menos distúrbios aos animais, se os indicadores forem usados para se estimar a produção fecal. 


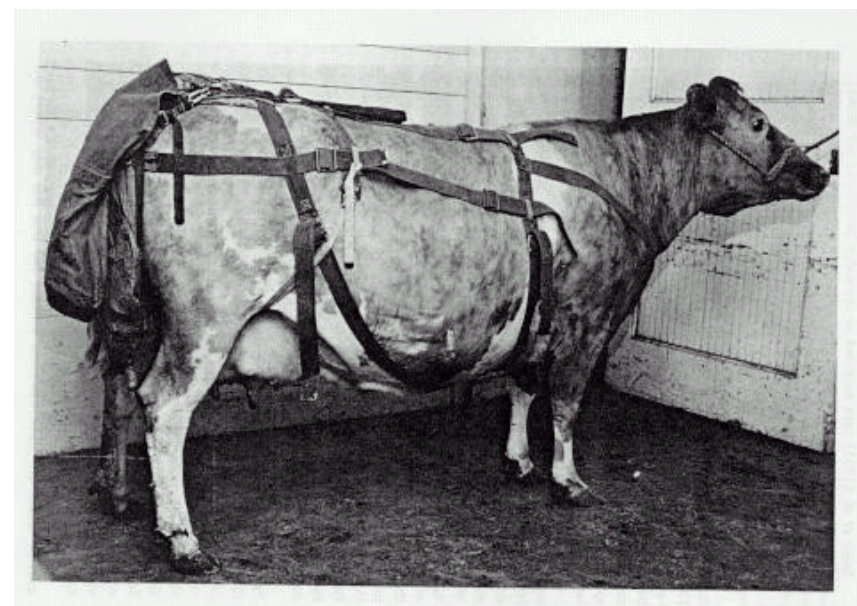

Figura 3 - Arreio para coleta de fezes (Garrigus, 1934).

Na técnica de duplo alcanos, um ralcano sintético, fornecido em quantidades conhecidas é utilizado para se determinar a produção fecal, juntamente com um n-alcano de cadeia ímpar encontrado naturalmente nas plantas e responsável pelas estimativas de digestibilidade.

O n-alcano externo pode ser fornecido aos animais diariamente em péletes, ou através de uma cápsula de liberação contínua que é colocada dentro do rúmen do animal. A vantagem de se utilizar esta cápsula é que os animais não precisam ser dosados diariamente, facilitando assim os estudos com animais selvagens. Segundo Mayes et al. (2001), utilizando estas cápsulas de liberação contínua juntamente com aparelhos de rastreamento via satélite, foi possível medir o consumo de alces, em florestas boreais.

O primeiro trabalho que utilizou a técnica de duplo alcano foi desenvolvido por Mayes et al. (1986) onde, estudando a recuperação fecal dos n-alcanos $C_{27}$ a $C_{35}$, encontrados naturalmente na forragem (Lolium perenne), e dos n-alcanos sintéticos $\mathrm{C}_{28} \mathrm{e}$ $\mathrm{C}_{32}$, em ovinos, constataram que a recuperação fecal dos n-alcanos encontrados naturalmente nas forragens, aumentava conforme aumentava o número de carbonos da cadeia. Perceberam também, uma grande similaridade entre a recuperação dos n-alcanos naturais com a dos sintéticos fornecidos oralmente, quando estes apresentam 
subseqüentes números de carbono em sua cadeia, sendo que o $\mathrm{C}_{28}$ apresentou um leve aumento de sua recuperação fecal em relação ao $\mathrm{C}_{27}$ e $\mathrm{C}_{29}$ e que o $\mathrm{C}_{32}$ teve a mesma recuperação do $C_{33}$. A média de ingestão estimada usando os ralcanos $C_{33}$ e $C_{32}$ foi idêntica com a ingestão da forragem observada. Outros pares de n-alcanos subestimaram levemente a ingestão da forragem sendo 3,5\% para os pares $\mathrm{C}_{28} \mathrm{C}_{29}$ e 7,6\% para os pares $\mathrm{C}_{27}-\mathrm{C}_{28}$. Estes resultados sugeriram que a estimativa da ingestão de forragem em ovinos seria possível através da utilização simultânea do n-alcano $C_{32}$ sintético e do $C_{33}$, encontrado naturalmente nas plantas.

Estimar a digestibilidade da matéria seca e a ingestão em nove cervos-nobre (Cervus elaphus canadensis) através da técnica de duplo alcano, foi o objetivo do trabalho desenvolvido por Gedir \& Hudson (2000). Os animais receberam uma cápsula de liberação controlada contendo os n-alcanos $\mathrm{C}_{32}$ e $\mathrm{C}_{36}$ como marcadores externos. A ingestão de matéria seca estimada pelo $\mathrm{C}_{33} \cdot \mathrm{C}_{32}$ foi ligeiramente mais acurada em relação ao $\mathrm{C}_{31}: \mathrm{C}_{32}$, porém o $\mathrm{C}_{31}: \mathrm{C}_{32}$ foi ligeiramente mais preciso do que o $\mathrm{C}_{33}: \mathrm{C}_{32}$ para predizer a ingestão. A digestibilidade da dieta (alfafa) foi obtida através do uso do n-alcano $\mathrm{C}_{36}$ como um indicador da produção fecal que, juntamente com o valor estimado do consumo resultou em um coeficiente de 63\%. Os autores relataram, também, que os níveis de ingestão não afetaram significativamente a taxa de excreção do marcador, a digestibilidade do alimento, a recuperação fecal dos n-alcanos e que a técnica de duplo alcano pode fornecer medidas precisas e acuradas da ingestão de matéria seca em cervos-nobre alimentados com dietas uniformes. Porém, sob condições de pastejo é importante selecionar quais n-alcanos seriam adequados e ter um acurado conhecimento da dieta.

Trabalhando com girafas em cativeiro, Hatt et al. (1998) concluíram que o método dos nalcanos foi válido e não invasivo, sendo uma opção para estudos da cinética ingestiva com estes animais em cativeiro e, possivelmente, em outros herbívoros não domésticos. Os resultados para composição da dieta, ingestão e digestibilidade foram inconstantes e não foram totalmente congruentes com as medidas diretas. Variações diurnas nas concentrações fecais dos nalcanos podem ter sido um problema, assim como as baixas concentrações dos nalcanos, em certos componentes da dieta. Os 
autores sugeriram que em futuros estudos as girafas deverão ser dosadas duas vezes ao dia, e as amostras fecais coletadas várias vezes ao dia. Durante esse estudo as girafas mostraram baixos coeficientes de digestibilidade, e um curto tempo de retenção das partículas comparado aos ruminantes "grazers". Isto suporta a idéia de que as girafas semelhante a muitas espécies "browsers", não são capazes de digerir eficientemente alimentos volumosos. Esses autores observaram também, que alimentos com baixas concentrações de n-alcanos ( $<10 \mathrm{mg} / \mathrm{kg}$ MS) não foram adequados para estudos da composição da dieta em girafas e, provavelmente, não serão com outros herbívoros.

\subsubsection{Utilização dos n-alcanos nas estimativas da composição botânica}

Para os herbívoros selvagens, o maior consumo de algumas espécies de plantas, em relação a outras não tem apenas um efeito nutricional sobre o animal, porém também tem uma importante influência sobre a sustentabilidade ecológica de uma comunidade de plantas.

Os procedimentos para se estimar a composição da dieta em herbívoros e seus problemas associados têm sido revisto em detalhes por Norbury \& Sanson (1992). Observações diretas do comportamento alimentar têm sido amplamente usadas para se obter o tempo de alimentação em diferentes comunidades de plantas e, deste modo obter indicativos da composição da dieta (Norbury \& Sanson, 1992). Este método é mais fácil, quando aplicado em situações nas quais as diferentes plantas apresentam uma separação espacial. Embora técnicas de vídeo tenham facilitado o procedimento, pois permitem observações por um longo período, a principal desvantagem deste método é a dificuldade de se converter o tempo de pastejo ou o número de bocados, para uma planta em particular.

A observação do conteúdo estomacal após a morte do animal também tem sido amplamente utilizada na estimativa da composição da dieta em herbívoros selvagens (Sanson, 1992). Porém, este método não permite que variações temporais possam ser estudadas além de que o método pode representar a dieta consumida durante um curto 
período de tempo antes da morte do animal. Plantas com diferentes digestibilidades podem ser as fontes de erro.

Muitos estudos de taxonomia têm mostrado diferenças nos perfis de n-alcanos da cera cuticular das plantas (Tulloch et al. 1980; Tulloch, 1981). Estas variações encontradas nas concentrações dos diferentes n-alcanos, entre as espécies vegetais, podem ser exploradas no sentido de fornecer informações sobre a composição da forragem consumida.

Algumas estimativas podem ser obtidas utilizando-se equações simultâneas (Dove, 1991). Porém, um número de aspectos deve ser levado em consideração (Dove \& Mayes 1991):

1- Quanto maior for a diferença entre os perfis de n-alcanos, maior será a sensibilidade das estimativas;

2- O número máximo de espécies a ser separada, é limitado ao número de nalcanos utilizados nas estimativas. Para se conseguir uma solução com equações simultâneas, o número de alcanos deve ser igual ao número de espécies;

3- Na hora de escolher os n-alcanos, deve-se dar preferência a aqueles que se diferenciam mais entre as espécies.

Outro fator importante que deve ser considerado durante as estimativas da composição botânica é que devido à recuperação fecal incompleta dos nalcanos, estas devem ser corrigidas antes de serem utilizadas. Estimativas diretas das recuperações fecais dos n-alcanos não são possíveis de serem obtidas com os animais em pastejo, porém medidas de recuperações obtidas em experimentos de coleta total de fezes podem ser utilizadas (Dove \& Mayes, 1991).

Segundo Hulbert et al. (2001), uma dieta relativamente simples, apresentando diferenças significativas nos perfis de ralcanos, foi o fator determinante na estimativa da composição botânica em lebres. 


\section{MATERIAL E MÉTODOS}

\subsection{Local}

Este estudo foi delineado pelo Laboratório de Nutrição e Crescimento Animal, na Escola Superior de Agricultura "Luiz de Queiroz" - USP, em parceria com a Faculdade de Ciências Agrárias e Veterinária de Jaboticabal - UNESP, onde foi realizada toda parte de campo. Os animais experimentais estavam localizados no setor de animais silvestres ligado ao Departamento de Zootecnia da FCAV/UNESP.

\subsection{Animais experimentais e dieta}

Oito veados catingueiros (Mazama gouazoubira), sendo quatro machos e quatro fêmeas adultos, pesando em média $17 \mathrm{~kg} \pm 1,8$ foram utilizados durante o experimento. Os animais receberam uma dieta peletizada composta por 63,9\% de feno de alfafa (Medicago sativa), 16,9\% de amido de milho, 14,7\% de levedura (Saccharomyces cerevisiae), 2,5\% de melaço, $1,5 \%$ de um premix vitamínico-mineral e $0,5 \%$ de cloreto de sódio.

A dieta peletizada foi utilizada para que todos os animais recebessem as mesmas proporções dos nutrientes, e para evitar que houvesse seletividade, sendo seus valores bromatológicos apresentados na Tabela 1. Através da Tabela 2 pode-se observar os níveis de garantia do premix vitamínico mineral utilizado na dieta. 
Tabela 1. Valores bromatológicos da dieta oferecida aos animais durante o período de coleta (valores em $100 \%$ de matéria seca)

\begin{tabular}{lc}
\hline \multicolumn{1}{c}{ Componentes Bromatológicos } & $(\%)$ \\
\hline Matéria seca & 87,9 \\
Matéria orgânica & 90,8 \\
Matéria mineral & 9,2 \\
Proteína bruta & 19,4 \\
Extrato etéreo & 1,2 \\
FDN & 29,5 \\
Hemicelulose & 6,0 \\
Celulose & 17,7 \\
Lignina & 5,1 \\
Energia bruta $(\mathrm{kcal} / \mathrm{g})$ & 4,25 \\
\hline
\end{tabular}

Tabela 2. Níveis de garantia do premix vitamínico mineral por kg

\begin{tabular}{llll}
\hline \multicolumn{2}{c}{ Suplemento vitamínico } & \multicolumn{2}{c}{ Suplemento mineral } \\
\hline Vitamina A & $2.500 .000,000 \mathrm{UI}$ & Ferro & $60.000,000 \mathrm{mg}$ \\
Vitamina D3 & $500.000,000 \mathrm{UI}$ & Manganês & $40.000,000 \mathrm{mg}$ \\
Vitamina E & $1.250,000 \mathrm{mg}$ & Zinco & $40.000,000 \mathrm{mg}$ \\
Antioxidante & $3.750,000 \mathrm{mg}$ & Cobre & $15.000,000 \mathrm{mg}$ \\
Veículo q.s.p. & $1.000,000 \mathrm{~g}$ & Iodo & $1.200,000 \mathrm{mg}$ \\
& & Selênio & $120,000 \mathrm{mg}$ \\
& & Cobalto & $500,000 \mathrm{mg}$ \\
& & Veículo q.s.p. & $1.000,000 \mathrm{~g}$ \\
\hline
\end{tabular}




\subsection{Experimento de digestibilidade com coleta total}

Os animais foram submetidos a um período de adaptação à dieta, de 30 dias. Antes do início do período de coleta, todos os animais foram pesados e alojados individualmente em baias medindo 2 × $4 \mathrm{~m}$ sendo possível a obtenção dos valores de consumo 24 h antes do início da coleta das fezes. Não foi possível a utilização de gaiolas metabólicas, porque alguns animais do grupo não eram dóceis o suficiente e poderiam apresentar queda de consumo e outros sinais de estresse, interferindo nos dados de digestibilidade. O período de coleta de fezes foi de 5 dias e, durante este período os animais foram alimentados diaria mente às $14 \mathrm{~h}$, e a água foi fornecida à vontade. As sobras do dia anterior eram retiradas diariamente, pesadas e amostradas para posterior análise. A ingestão de água diária foi determinada com o auxílio de uma proveta, sendo seus valores corrigidos para evaporação. Esta correção foi feita, subtraindo as quantidades evaporadas diariamente de um recipiente referência semelhante aos fornecidos aos animais, colocado do lado externo das baias. As fezes foram coletadas em intervalos de 10 minutos, $24 \mathrm{~h}$ por dia durante os cinco dias com o intuito de minimizar as contaminações com o piso e a urina dos animais, sendo esta facilitada pelo motivo dos animais determinarem áreas de latrina. A remoção das fezes foi feita com o auxílio de uma pá de plástico e uma escova, sendo em seguida armazenada em um isopor com gelo. Antes das análises laboratoriais, os pêlos foram removidos utilizando-se um secador de cabelo e os remanescentes, retirados manualmente.

\subsection{Análises bromatológicas}

As amostras de alimento, sobras e fezes foram secas em estufa a $65^{\circ} \mathrm{C}$ por $72 \mathrm{~h}$, e em seguida submetidas à moagem em peneira com malha de1 $\mathrm{mm}$ de diâmetro para posterior determinação da matéria seca a $105^{\circ} \mathrm{C}$. A determinação da matéria mineral foi realizada através da queima das amostras na mufla a $550^{\circ} \mathrm{C}$ por 3 horas, fornecendo através da subtração desta fração, também os valores de matéria orgânica. Análises do 
nitrogênio foram feitas pelo procedimento de micro-Kjeldahl e a energia bruta analisada pela bomba calorimétrica adiabática. As extrações das frações lipídicas das amostras foram feitas através da utilização de um solvente (éter de petróleo) em aparelho Soxhlet. As demais análises de FDN, hemicelulose, celulose e lignina foram realizadas pelo método de Goering \& Van Soest (1970).

Durante as análises bromatológicas, encontrouse dificuldade na filtragem para a determinação da fibra em detergente neutro (FDN), porque as amostras de fezes e da dieta obstruíram o filtro dos cadinhos. Através da utilização da enzima alfa-amilase termo-estável junto a uma solução de uréia a 8 M segundo Van Soest et al. (1991) descartou-se a hipótese de que a inclusão de 16,9\% do amido de milho, utilizado como um dos componentes da dieta, fosse a responsável pela obstrução dos cadinhos. Estudando a composição química da levedura de cana, utilizada em 14,7\% da dieta, observou-se que esta é constituída de $15 \%$ a $60 \%$ de carboidratos, sendo que aproximadamente $33 \%$ é representado por trealoses, $27 \%$ por glucanas, $21 \%$ por mananas e $12 \%$ por glicogênio. A trealose é um dissacarídeo não redutor formado por duas moléculas de glicose. Já as glucanas e mananas são polissacarídeos não redutores, presentes na parede celular das leveduras e formados por moléculas de glicose e manose, respectivamente (Rose \& Harrison, 1970). Por apresentarem diferentes ligações glicosídicas não compatíveis com as enzimas utilizadas durante os procedimentos laboratoriais, estes carboidratos foram os principais responsáveis pelas dificuldades de filtragem, sendo que apenas um complexo enzimático específico poderia romper todas essas ligações, tornando inviáveis tais análises. Segundo Mertens (comunicação pessoal), uma solução factível para esse problema, seria a utilização de uma areia tratada, conhecida como "Seesand" (Fluka®). Esta é responsável pela não obstrução dos cadinhos, aderindo-se aos carboidratos e impedindo sua fixação no filtro dos cadinhos. Porém, deve-se ressaltar que embora a areia facilite a filtragem das amostras, o material contaminante fica intimamente ligado a ela, não permitindo com que os valores reais das frações da fibra sejam computados. Devido a alfafa ter sido utilizada como única fonte de fibra da dieta, os valores de FDN, hemicelulose, celulose e lignina utilizados nos cálculos de digestibilidade poderiam ter sido obtidos simplesmente determinando estas 
frações no feno de alfafa e conhecendo sua contribuição na dieta. Porém, nas fezes, devido a falta de estudos sobre a digestibilidade do feno de alfafa com essa espécie de cervídeo, juntamente com a falta de informações sobre o efeito interativo dos componentes da dieta, os valores de FDN, hemicelulose, celulose e lignina teriam que ser computados junto com a fração contaminante o que resultaria em uma subestimativa dos coeficientes de digestibilidade.

Uma alternativa, visando minimizar os erros dessas frações nas fezes, veio através de análises seqüenciais, onde o FDN, hemicelulose, celulose e lignina foram obtidos por diferença de peso esperando que no final das análises apenas o contaminante fosse encontrado junto às cinzas. A hemicelulose foi obtida através da determinação da fração solúvel entre os procedimentos de FDN e FDA. Em seguida, ao cadinho contendo a fração FDA, foi adicionada uma solução de ácido sulfúrico $72 \%$, para que a celulose fosse solubilizada restando apenas a lignina junto a fração contaminante. Esta por sua vez, foi obtida através da utilização de uma solução de permanganato de potássio. Somando-se estas três frações obtinha-se também o FDN. Porém, durante estas análises observou-se que a fração contaminante foi solubilizada parcialmente com as frações desejadas, interferindo nos resultados. Segundo Cook (1958), o ácido sulfúrico utilizado durante o presente estudo na determinação da celulose, é também utilizado tanto nas extrações das glucanas, assim como nas extrações de trealoses e mananas, sendo um dos principais responsáveis pela solubilização destes compostos durante as análises seqüenciais, alterando ainda mais os valores de FDN, hemicelulose, celulose e lignina dos valores reais. Por este motivo optourse em utilizar os valores obtidos junto com o contaminante, tanto para as fezes quanto para a dieta durante os cálculos de digestibilidade.

\subsection{Cálculos de digestibilidade}

Para os cálculos de digestibilidade dos nutrientes foi utilizada a equação 1, segundo Schneider \& Flatt (1975): 


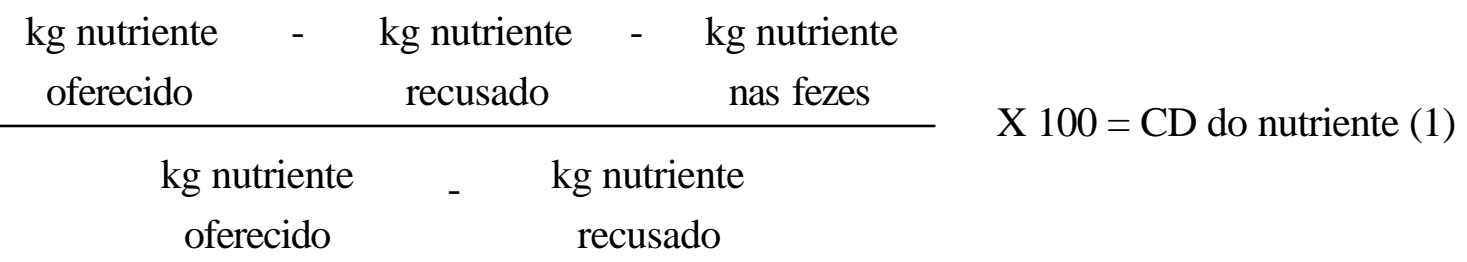

\subsection{Extração dos n-alcanos das amostras de alimentos e fezes}

Durante o presente estudo, amostras de fezes e da dieta foram saponificadas diretamente segundo Dillon \& Stakelum (1990). Além disso, duas outras modificações foram feitas durante este trabalho: a) o bloco aquecedor foi substituído pelo "banhomaria" e b) ao invés da utilização de colunas foram utilizadas seringas plásticas descartáveis de $5 \mathrm{~mL}$. O padrão interno utilizado nas amostras de fezes e alimento durante as análises cromatográficas foi o nalcano $C_{34}$. Porém, análises da dieta sem a utilização do padrão, foram realizadas com o objetivo de se determinar se esta apresentava o n-alcano $\mathrm{C}_{34}$, naturalmente em seu perfil de n-alcanos. Se detectado, estes valores seriam subtraídos dos valores totais de $\mathrm{C}_{34}$ das amostras com o padrão, evitando com que este n-alcano ficasse superestimado, em relação aos outros.

Os procedimentos utilizados para extração dos n-alcanos neste trabalho foram os seguintes:

1- Foram utilizados $0,5 \mathrm{~g}$ de fezes e $1,5 \mathrm{~g}$ da dieta, colocados em tubos de ensaio, com tampa de rosca, medindo $20 \mathrm{~mm}$ x $100 \mathrm{~mm}$ e $22 \mathrm{~mm}$ x $200 \mathrm{~mm}$, respectivamente;

2- Como padrão interno utilizourse $0,13 \mathrm{mg} / \mathrm{mL}$ do tetratriacontano $\left(\mathrm{C}_{34} \mathrm{H}_{70}\right)$, diluído em heptano;

3- Em seguida, foram acrescentados $7 \mathrm{~mL}$ de Hidróxido de Potássio (1 M) para as amostras de fezes, e $14 \mathrm{~mL}$ para as amostras de alimento, que permaneceram em repouso por 30 minutos;

4- Após os 30 minutos, os tubos foram aquecidos em "banho-maria" por $4 \mathrm{~h}$ a $90^{\circ} \mathrm{C}$; 
5- Posteriormente, foram adicionados $7 \mathrm{~mL}$ de heptano, e $2 \mathrm{~mL}$ de água destilada para as amostras de fezes, e $14 \mathrm{~mL}$ de heptano e $4 \mathrm{~mL}$ de água destilada para as amostras do alimento, sendo os tubos agitados por 30 segundos em aparelho de vortex;

6- A camada sobrenadante foi transfe rida para um "beaker" de $50 \mathrm{~mL}$;

7- Em seguida foram adicionados mais $7 \mathrm{~mL}$ de heptano para as amostras de fezes, e 14 $\mathrm{mL}$ para as amostras de alimento, sendo os tubos agitado por mais 30 segundos em vortex e o sobrenadante novamente transferido ao mesmo "beaker";

8- O material contido no "beaker", foi evaporado à temperatura ambiente, e em seguida redissolvido em 1,5 $\mathrm{mL}$ de heptano;

9- Este material foi aplicado em uma coluna de sílica-gel (60 mesh) suspensa em heptano. A coluna foi obtida através da utilização de seringas descartáveis segundo Oliveira et al. (2002), sendo que na ponta inferior da seringa foi utilizado como filtro, algodão lavado com éter de petróleo durante $24 \mathrm{~h}$ em aparelho Soxhlet;

10- Os hidrocarbonetos foram eluídos em $10 \mathrm{~mL}$ de heptano, em pequenos vid ros, e em seguida o heptano foi evaporado, ficando somente os hidrocarbonetos;

11- Antes de serem levados à cromatografia, os hidrocarbonetos foram rediluídos em $1,9 \mathrm{~mL}$ de heptano.

\subsection{Análises de cromatografia gasosa}

Para as análises dos hidrocarbonetos, foi utilizada uma coluna capilar CP-SIL 8CB (Crompack), com $30 \mathrm{~m}$ x 0,25 mm x 0,1 $\mu \mathrm{m}$ de espessura de filme. O cromatógrafo utilizado foi um Thermoquest com detector de ionização de chama. Dois microlitros de amostra foram injetados em uma coluna cromatográfica com uma razão de "split" 20:1, através de um sistema de injeção automática e a uma temperatura de $280^{\circ} \mathrm{C}$. Na coluna a temperatura inicial foi de $200^{\circ} \mathrm{C}$ subindo $6^{\circ} \mathrm{C}$ por minuto até atingir uma temperatura final de $300^{\circ} \mathrm{C}$ por 15 minutos. O gás carregador utilizado foi o hélio, com velocidade linear de $32 \mathrm{~cm} / \mathrm{segundo}$, já os gases de chama utilizados foram o nitrogênio, hidrogênio e oxigênio com taxas de fluxo de 30,35 e $430 \mathrm{~mL} /$ minuto, respectivamente. Para a identificação dos diferentes n-alcanos, foram utilizadas análises de regressão e 
correlação entre os tempos de retenção de cada n-alcano, com os respectivos números de carbono de sua cadeia (Debbrecht, 1985).

Para que as áreas dos picos cromatográficos fossem transformados em quantidades de ralcanos (mg), através da utilização de quantidades conhecidas de um padrão interno $\left(\mathrm{C}_{34} \mathrm{H}_{70}\right)$, utilizou-se a seguinte fórmula segundo Mc Nair \& Bonnelli (1968):

$$
C x=\frac{\text { Qp x Ax }}{\text { Frx } \times \text { Ap }}
$$

sendo que o Cx representa o ralcano a ser identificado (mg), o Qp a quantidade de padrão interno adicionado a amostra (mg), o Ax a área do nalcano a ser identificado, o Frx o fator de resposta do nalcano a ser identificado e o Ap representa a área do padrão interno no cromatograma.

O fator de resposta foi determinado para cada n-alcano em relação ao padrão interno (C 34 ) segundo a equação descrita por Untz (1982):

$$
\operatorname{Frn}=\frac{\mathrm{N}^{\circ} \mathrm{C}_{n} / \text { Massa Molecular } \mathrm{C}_{n} \mathrm{H}_{2 \mathrm{n}+2}}{\mathrm{~N}^{\circ} \mathrm{C}_{34} / \text { Massa Molecular } \mathrm{C}_{34} \mathrm{H}_{70}}
$$

de maneira que o Frn representa o fator de resposta do n-alcano a ser calculado, e o Cn o número de carbonos do respectivo n-alcano a ser calculado.

\subsection{Cálculos de digestibilidade através do uso de um indicador interno}

A determinação da digestibilidade da matéria seca foi realizada pela fórmula abaixo segundo Schneider \& Flatt (1975):

$\%$ indicador na matéria seca

Coeficiente de digestão do alimento da matéria seca $=100-100 \mathrm{x}$ das fezes 
A estimativa da digestibilidade dos diferentes nutrientes, foi calculada segundo a fórmula de Schneider \& Flatt (1975):

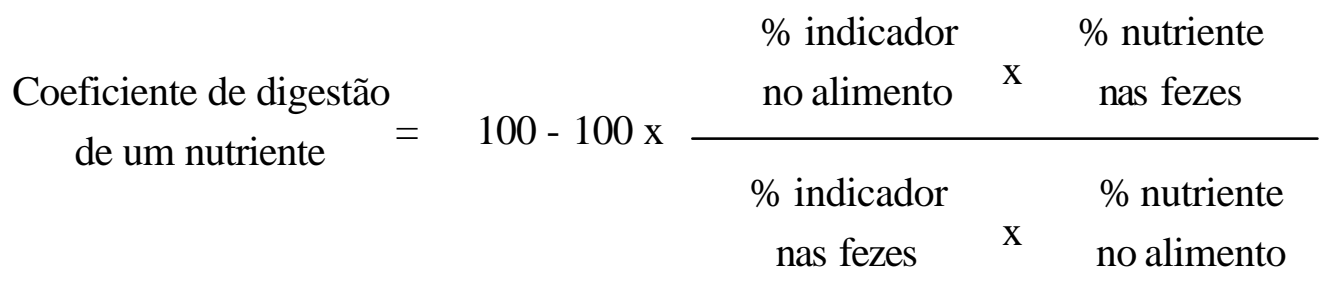

Já a determinação dos coeficientes de digestibilidade, corrigidos para a recuperação fecal média dos n-alcanos $C_{31}$ e $C_{33}$, foi realizado através da equação sugerida por Lucas (1952).

$$
\begin{gathered}
\text { Coeficiente de digestão } \\
\text { de um nutriente }
\end{gathered}=100-\frac{\begin{array}{c}
\text { \% recuperação } \\
\text { do indicador }
\end{array}}{\frac{\begin{array}{c}
\% \text { indicador } \\
\text { nas fezes } \\
\text { no alimento }
\end{array}}{\mathrm{X}} \text { no alimento }}
$$

\subsection{Análises estatísticas}

Análises de regressões foram realizadas, entre os coeficientes de digestibilidade observados e estimados com os nalcanos $\mathrm{C}_{31}$ e $\mathrm{C}_{33} \mathrm{e}$, para determinar a precisão da metodologia testou-se se o coeficiente angular (b) diferiu de 1. Em seguida, através do teste "t" para comparações de médias emparelhadas, determinourse a acurácia entre as médias dos coeficientes de digestibilidade observados e os estimados com os indicadores. Foram realizadas, também, análises utilizando o teste "t" para comparações de médias emparelhadas entre os coeficientes de digestibilidade observados e os estimados com os ralcanos $\mathrm{C}_{31}$ e $\mathrm{C}_{33}$, ajustados para o valor médio de recuperação fecal. Todas as análises foram realizadas pelo programa computacional SAS (SAS, 1999). 


\section{RESULTADOS E DISCUSSÃO}

\subsection{Consumo de alimento e água}

As médias do consumo de alimento e água obtidas durante o período de coleta podem ser observadas através das Figuras 4 e 5 e da Tabela 3.

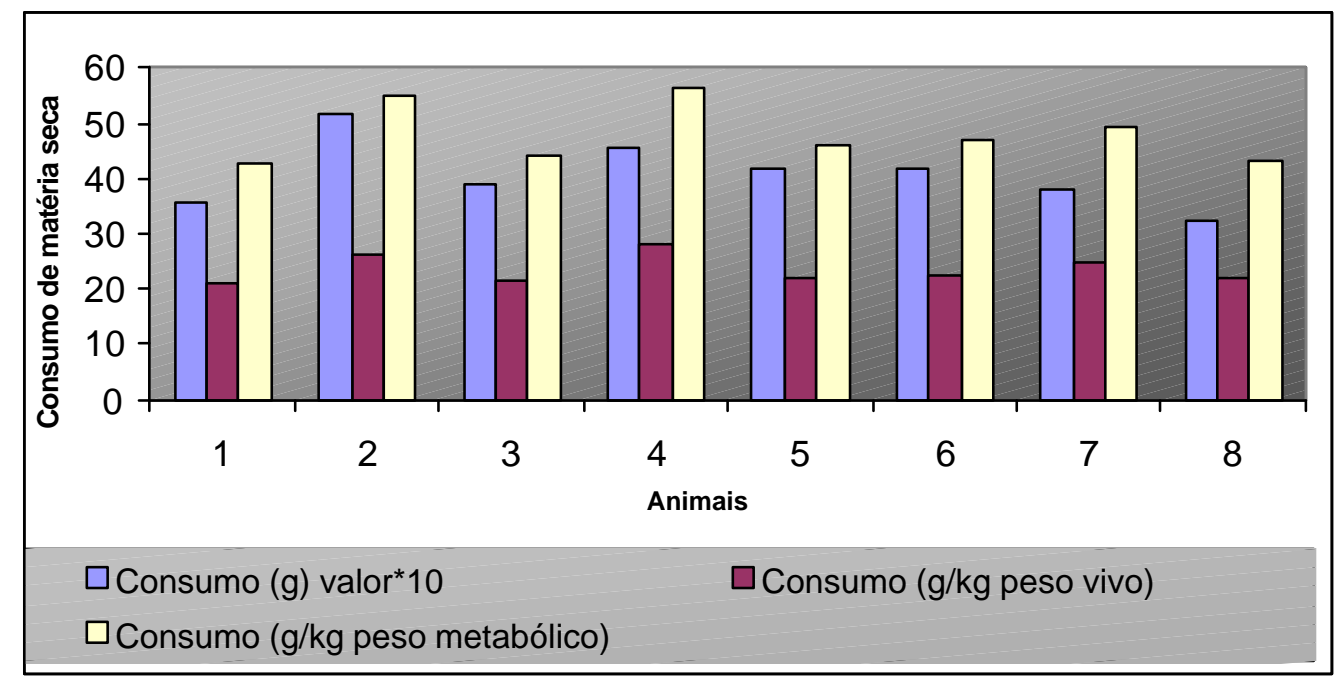

Figura 4 - Consumo de matéria seca em 8 veados catingueiro 


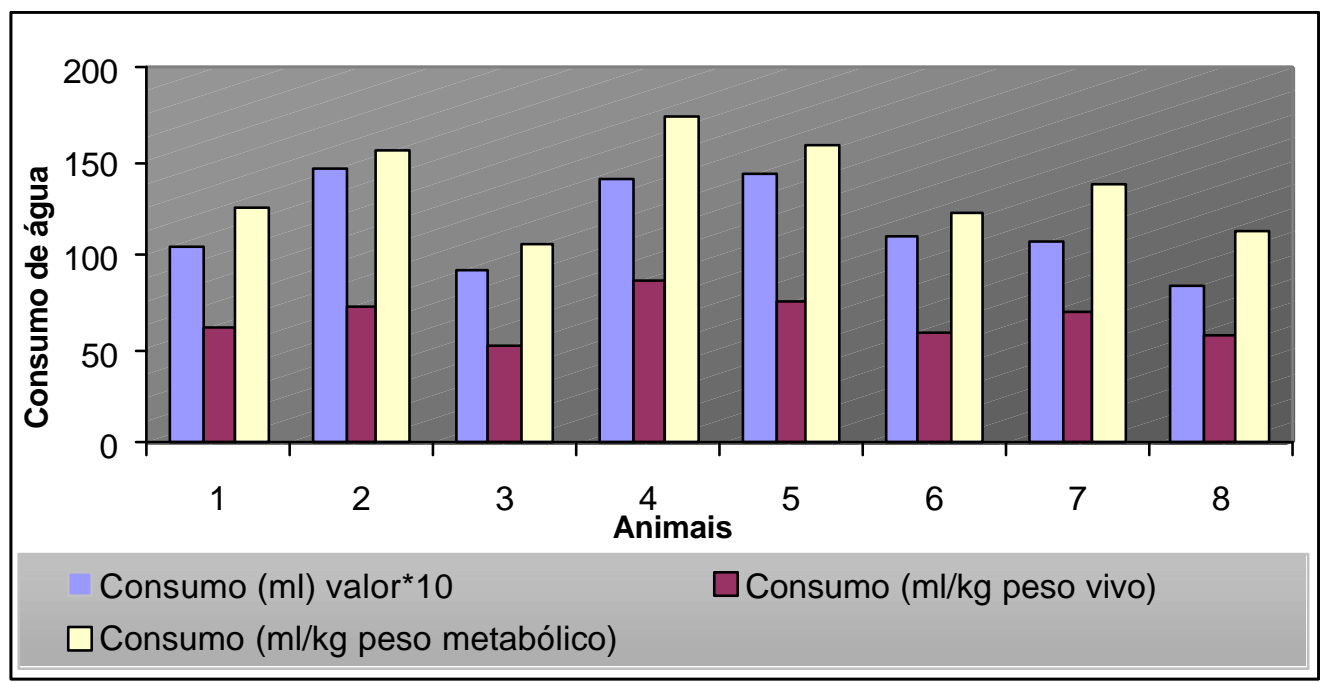

Figura 5 - Consumo de água em 8 veados catingueiro

Tabela 3. Médias do consumo de matéria seca e água obtidas durante o período de coleta

\begin{tabular}{ccccccc}
\hline \multicolumn{7}{c}{ Matéria seca } \\
Animais & $\begin{array}{c}\text { Consumo } \\
\text { Original }(\mathrm{g})\end{array}$ & $\begin{array}{c}\text { Consumo } \\
(\mathrm{g} / \mathrm{kg} P \mathrm{PV})\end{array}$ & $\begin{array}{c}\text { Consumo } \\
\left(\mathrm{g} / \mathrm{kg} \mathrm{o}^{0,75}\right)\end{array}$ & $\begin{array}{c}\text { Consumo } \\
\text { Original }(\mathrm{mL})\end{array}$ & $\begin{array}{c}\text { Consumo } \\
(\mathrm{mL} / \mathrm{kg} P V)\end{array}$ & $\begin{array}{c}\text { Consumo } \\
\left(\mathrm{mL} / \mathrm{kg}^{0,75}\right)\end{array}$ \\
\hline 1 & $358,2 \pm 60,0$ & $21,1 \pm 3,5$ & $42,8 \pm 7,2$ & $1.046 \pm 170,4$ & $61,6 \pm 10,0$ & $125,1 \pm 20,4$ \\
2 & $516,8 \pm 33,3$ & $26,1 \pm 1,7$ & $55,1 \pm 3,6$ & $1.452 \pm 159,9$ & $73,4 \pm 8,1$ & $155,0 \pm 17,1$ \\
3 & $387,8 \pm 42,5$ & $21,5 \pm 2,4$ & $44,3 \pm 4,9$ & $932 \pm 171,7$ & $51,6 \pm 9,5$ & $106,5 \pm 19,6$ \\
4 & $456,1 \pm 45,6$ & $28,1 \pm 2,8$ & $56,4 \pm 5,6$ & $1.402 \pm 292,7$ & $86,4 \pm 18,0$ & $173,5 \pm 36,2$ \\
5 & $417,8 \pm 13,5$ & $22,1 \pm 0,7$ & $46,1 \pm 1,5$ & $1.428 \pm 173,3$ & $75,7 \pm 9,2$ & $157,8 \pm 19,1$ \\
6 & $417,7 \pm 44,2$ & $22,6 \pm 2,4$ & $46,9 \pm 5,0$ & $1.093 \pm 171,4$ & $59,2 \pm 9,3$ & $122,8 \pm 19,3$ \\
7 & $378,6 \pm 56,9$ & $24,9 \pm 3,7$ & $49,1 \pm 7,4$ & $1.068 \pm 201,2$ & $70,2 \pm 13,2$ & $138,7 \pm 26,1$ \\
8 & $323,3 \pm 60,1$ & $22,1 \pm 4,1$ & $43,3 \pm 8,0$ & $836 \pm 293,3$ & $57,2 \pm 20,1$ & $111,9 \pm 39,3$ \\
Média e & $407,0 \pm 60,1$ & $23,6 \pm 2,5$ & $48,0 \pm 5,2$ & $1.157 \pm 238,6$ & $66,9 \pm 11,5$ & $136,4 \pm 23,9$ \\
DP & & & & & & \\
\hline PV = Peso vivo
\end{tabular}

Os veados catingueiro, durante esse período, apresentaram certos padrões de alimentação. Durante as primeiras horas da manhã e ao final da tarde, os animais foram com maior frequiência ao cocho em relação às horas mais quentes do dia, deixando-as 
reservadas para ruminação. Este comportamento demonstrou que a temperatura pode ter influenciado no consumo de matéria seca, durante as horas mais quentes do dia, porém análises de regressões indicaram que as médias diárias de temperatura, não tiveram influências significativas no consumo de matéria seca $(\mathrm{P}>0,05)$. Há trabalhos que mostraram que esta espécie não apresenta picos de atividade bem definidos, sendo às vezes diurna e às vezes diurna e noturna (Santos, 1984). Segundo Short (1975), altas temperaturas parecem reduzir o consumo de alimentos em veados de cauda branca e este mesmo fenômeno foi observado por Parker \& Robbins (1984), em veados mula (Odocoileus hemionus). A temperatura média diária também não apresentou um efeito significativo sobre o consumo de água nos veados catingueiro durante o período de coleta $(\mathrm{P}>0,05)$, não ultrapassando os $30^{\circ} \mathrm{C}$ e permanecendo dentro da zona termoneutra estabelecida por Taylor \& Lyman (1967). Segundo estes autores, discutindo a influência do aumento de temperatura sobre o consumo de água, descreveram uma zona termoneutra onde as mudanças de temperatura no ambiente não causam alterações no consumo de água, pelos animais. Deve-se, porém, considerar que a temperatura pode ter influenciado no consumo de água durante as horas mais quentes do dia, quando os valores de temperatura ultrapassaram facilmente os $30^{\circ} \mathrm{C}$.

Diferentes fatores podem afetar o consumo de água pelos animais. Através do experimento desenvolvido por Holter \& Urban (1992), com o objetivo de desenvolver equações para predizer a ingestão de água em vacas secas e lactantes, concluíram que a ingestão de matéria seca diária, e a porcentagem de matéria seca na dieta foram positivamente relacionadas à ingestão de água e foram parâmetros estatisticamente válidos para predição do consumo nestes animais. Do mesmo modo, a ingestão de matéria seca foi o principal fator responsável pelo aumento ou diminuição do consumo de água nos veados catingueiro $(\mathrm{P}<0,01)$ conforme pode-se observar na Figura 6. 


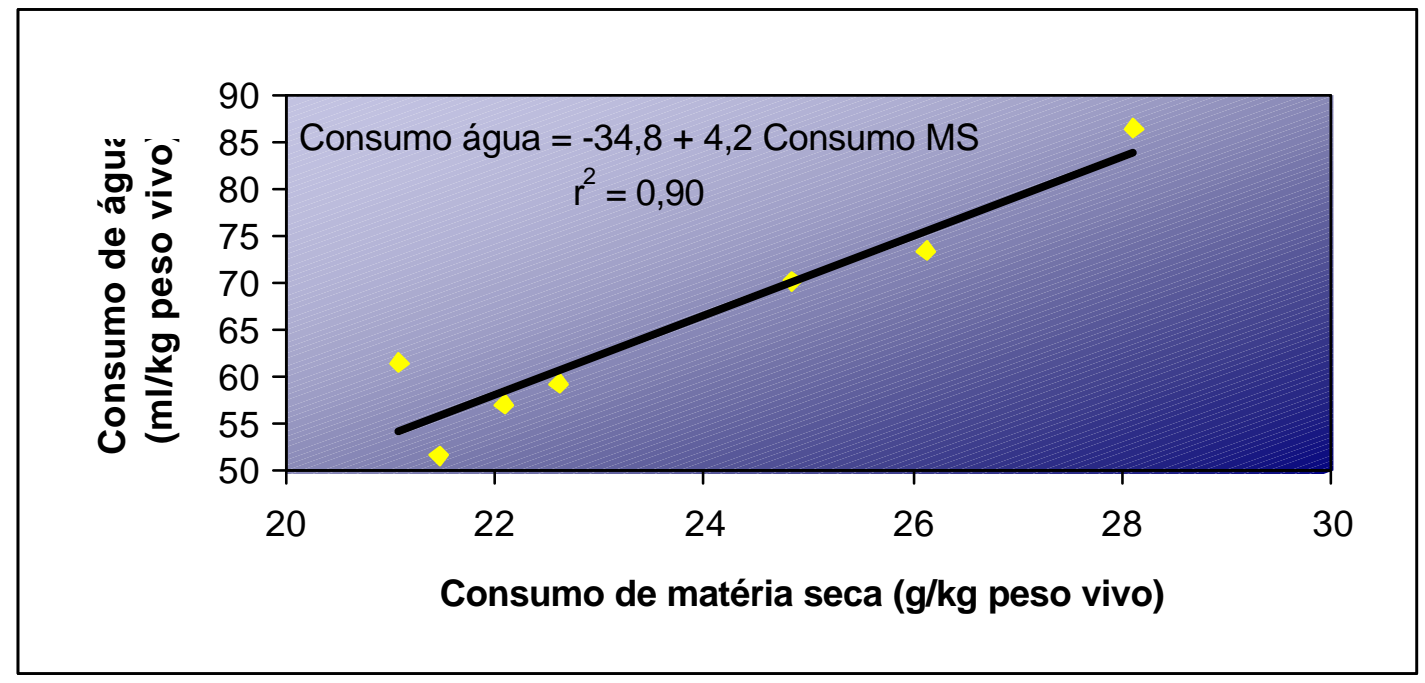

Figura 6 - Regressão entre as médias de consumo de matéria seca e as médias de ingestão de água em 7 veados catingueiro (Mazama gouazoubira) durante o período de coleta

Nenhum valor de consumo foi encontrado na literatura utilizando veados catingueiro, recebendo dietas semelhantes às fornecidas durante o presente estudo. Porém, estudando diferentes aspectos nutricionais em "blue duikers", com aproximadamente $4 \mathrm{~kg}$, Wenninger \& Shipley (2000), observaram que estes pequenos selecionadores de alimentos, recebendo uma dieta exclusivamente de alfafa recém colhida com 30,8\% de FDN, apresentaram valores de consumo próximos (50 g/ $\mathrm{kg}^{0,75}$ ) aos encontrados com os veados catingueiro. Já outros pequenos ruminantes como o veado-camundongo recebendo como dieta folhas de Sapium baccatum com 27,5\% de FDN, apresentaram em média um consumo de 42,4 g/kg $\mathrm{kg}^{0,75}$ (Nolan et al., 1995).

Com relação às espécies de ruminantes pesando acima de $20 \mathrm{~kg}$, trabalhos como o de Galbraith et al. (1998) e Semiadi et al. (1994) obtiveram valores de consumo superiores aos encontrados com os animais do presente estudo, mesmo recebendo dietas energeticamente muito semelhantes. Porém, deve-se ressaltar, que nestes trabalhos, os 
animais foram submetidos a dietas de alfafa com maiores proporções de FDN 59,2\% e $50,1 \%$ respectivamente, do que os veados catingueiro, e por esse motivo apresentaram uma redução na digestibilidade da dieta sendo obrigados a aumentar o consumo a fim de suprir suas exigências nutricionais.

\subsection{Digestibilidade através da coleta total de fezes}

Os coeficientes de digestibilidade obtidos durante o período de coleta podem ser observados na Tabela 4. 
Tabela 4. Consumo e digestibilidade dos nutrientes de oito veados catingueiros (Mazama gouazoubira) durante o período de coleta

\begin{tabular}{|c|c|c|c|c|c|c|c|c|c|c|c|c|}
\hline Animais & $\begin{array}{c}\text { Peso } \\
\text { Metabólico }\end{array}$ & $\begin{array}{c}\text { Consumo } 1 \\
\left(\mathrm{~g} / \mathrm{kg}^{0,75}\right)\end{array}$ & $\begin{array}{c}\text { Consumo } 2 \\
(\mathrm{~g} / \mathrm{kg} \mathrm{PV})\end{array}$ & $\begin{array}{c}\text { DMS } \\
\%\end{array}$ & $\begin{array}{c}\text { DMO } \\
\%\end{array}$ & $\begin{array}{c}\mathrm{DN} \\
\%\end{array}$ & $\begin{array}{c}\text { DEE } \\
\%\end{array}$ & $\begin{array}{c}\text { DEB } \\
\%\end{array}$ & $\begin{array}{c}\text { DFDN } \\
\%\end{array}$ & $\begin{array}{c}\mathrm{DH} \\
\%\end{array}$ & $\begin{array}{c}\mathrm{DC} \\
\%\end{array}$ & $\begin{array}{c}\mathrm{DL} \\
\%\end{array}$ \\
\hline 1 & 8,4 & 42,8 & 21,1 & 60,6 & 62,6 & 69,0 & 37,6 & 62,2 & 30,2 & 26,4 & 43,7 & 16,5 \\
\hline 2 & 9,4 & 55,1 & 26,1 & 59,7 & 62,1 & 64,9 & 45,4 & 61,1 & 30,3 & 20,8 & 44,1 & 18,7 \\
\hline 3 & 8,8 & 44,3 & 21,5 & 60,4 & 63,1 & 71,9 & 42,9 & 62,2 & 27,7 & 28,8 & 41,6 & 7,6 \\
\hline 4 & 8,1 & 56,4 & 28,1 & 62,3 & 64,7 & 70,5 & 22,9 & 63,4 & 33,8 & 41,0 & 46,1 & 22,4 \\
\hline 5 & 9,1 & 46,1 & 22,1 & 61,6 & 63,8 & 67,7 & 33,1 & 63,0 & 33,5 & 30,9 & 48,2 & 26,3 \\
\hline 6 & 8,9 & 46,9 & 22,6 & 64,3 & 66,6 & 69,8 & 37,5 & 65,4 & 38,6 & 50,0 & 47,1 & 23,0 \\
\hline 7 & 7,7 & 49,1 & 24,8 & 63,6 & 65,6 & 76,1 & 39,4 & 65,2 & 32,3 & 29,8 & 47,5 & 16,7 \\
\hline 8 & 7,5 & 43,3 & 22,1 & 60,4 & 62,6 & 67,4 & 56,1 & 61,4 & 27,3 & 15,6 & 43,0 & 19,3 \\
\hline $\begin{array}{c}\text { Média } \\
\text { DP }\end{array}$ & $\begin{array}{r}\mathbf{8 , 5} \\
\mathbb{0 , 7} \\
\end{array}$ & $\begin{array}{r}48,0 \\
+5,2 \\
\end{array}$ & $\begin{array}{c}24,0 \\
+2,5\end{array}$ & $\begin{array}{r}61,6 \\
\pm 1,7 \\
\end{array}$ & $\begin{array}{l}63,9 \\
\# 1,6\end{array}$ & $\begin{array}{r}69,7 \\
+3,4 \\
\end{array}$ & $\begin{array}{l}39,4 \\
\pm 9,6\end{array}$ & $\begin{array}{l}63,0 \\
\# 1,6\end{array}$ & $\begin{array}{r}31,7 \\
\mathbb{3}, 7 \\
\end{array}$ & $\begin{array}{r}30,4 \\
+10,9\end{array}$ & $\begin{array}{r}45,2 \\
\pm 2,4 \\
\end{array}$ & $\begin{array}{r}18,8 \\
\mathbb{5 , 6}\end{array}$ \\
\hline
\end{tabular}

Consumo 1, g/kg peso metabólico; Consumo 2, g/kg peso vivo; DMS, digestibilidade da matéria seca; DMO, diges tibilidade da matéria orgânica; DN digestibilidade do nitrogênio; DEE, digestibilidade do extrato etéreo; DEB, digestibilidade da energia bruta; DFDN, digestibilidade da fibra em

detergente neutro; DH, digestibilidade da hemicelulose; DC, digestibilidade da celulose; DL, digestibilidade da lignina 
De modo geral, durante o presente estudo os veados catingueiro mostraram-se eficientes na digestão de uma dieta composta por $63,9 \%$ de feno de alfafa, apresentando apenas baixos coeficientes de digestibilidade para as frações da fibra, com exceção da lignina e para o extrato etéreo quando comparados às outras espécies de ruminantes. Através das Tabelas 5 e 6, pode-se observar os coeficientes de digestibilidade obtidos por diferentes autores, utilizando diferentes espécies de ruminantes.

Tabela 5. Coeficientes de digestibilidade em espécies pesando menos de $20 \mathrm{~kg}$, recebendo dietas com diferentes concentrações de FDN

\begin{tabular}{|c|c|c|c|c|c|c|c|c|c|c|c|}
\hline Espécie & Dieta & $\begin{array}{l}D M S \\
(\%)\end{array}$ & $\begin{array}{c}D M O \\
(\%)\end{array}$ & $\begin{array}{l}D E \\
(\%)\end{array}$ & $\begin{array}{l}D P B \\
(\%)\end{array}$ & $\begin{array}{c}\text { DFDN } \\
(\%)\end{array}$ & $\begin{array}{c}\text { DFDA } \\
(\%)\end{array}$ & $\begin{array}{l}\mathrm{DH} \\
(\%)\end{array}$ & $\begin{array}{l}D C \\
(\%)\end{array}$ & $\begin{array}{l}D L \\
(\%)\end{array}$ & Referências \\
\hline $\begin{array}{c}\text { Cephalophus } \\
\text { monticola }\end{array}$ & 1 & 81,1 & & 80,3 & 80,6 & 66,7 & & & & & $\begin{array}{l}\text { Wenninger \& } \\
\text { Shipley } \\
\text { (2000) }\end{array}$ \\
\hline $\begin{array}{c}\text { Tragulus } \\
\text { javanicus }\end{array}$ & 2 & 81,2 & 83,8 & 77,8 & 63,7 & 72,1 & 60,5 & & & 56,0 & $\begin{array}{c}\text { Nolan et al. } \\
\text { (1995) }\end{array}$ \\
\hline Pudu pudu & & 75,2 & & & 77,4 & 58,8 & & 67,2 & 61,6 & 14,1 & \\
\hline $\begin{array}{c}\text { Mazama } \\
\text { americana }\end{array}$ & 3 & 73,2 & & & 75,0 & 54,3 & & 66,8 & 49,7 & 5,2 & $\begin{array}{c}\text { Conklin-Brittain } \\
\&\end{array}$ \\
\hline $\begin{array}{l}\text { Cephalophus } \\
\text { dorsalis }\end{array}$ & & 67,1 & & & 70,1 & 38,9 & & 48,8 & 39,5 & $-14,9$ & \\
\hline $\begin{array}{l}\text { Cephalophus } \\
\text { maxwellii }\end{array}$ & & 73,0 & & & 74,8 & 49,4 & & 55,0 & 53,2 & 7,7 & \\
\hline
\end{tabular}

Dietas: 1 - alfafa 30,8\% FDN; 2 - Sapium baccatum 27,5\% FDN; 3 - concetrado + alfafa peletizada + pequenas quantidades de vegetais $34,2 \% \mathrm{FDN}$.

DMS, digestibilidade da matéria seca; DMO, digestibilidade da matéria orgânica; DE, digestibilidade da energia; DPB, digestibilidade da proteína bruta; DFDN, digestibilidade da fibra em detergente neutro; DFDA, digestibilidade da fibra em detergente ácido; DH, digestibilidade da hemicelulose; DC, digestibilidade da celulose; DL, digestibilidade da lignina 
Tabela 6. Coeficientes de digestibilidade em espécies pesando mais de $20 \mathrm{~kg}$, recebendo dietas com diferentes concentrações de FDN

\begin{tabular}{|c|c|c|c|c|c|c|c|c|c|c|c|}
\hline Espécie & $\overline{\text { Dieta }}$ & $\begin{array}{l}\overline{D M S} \\
(\%)\end{array}$ & $\begin{array}{l}D M O \\
(\%)\end{array}$ & $\begin{array}{l}D E \\
(\%)\end{array}$ & $\begin{array}{l}\overline{D P B} \\
(\%)\end{array}$ & $\begin{array}{c}\overline{D F D N} \\
(\%)\end{array}$ & $\begin{array}{c}\overline{D F D A} \\
(\%)\end{array}$ & $\begin{array}{l}\mathrm{DH} \\
(\%)\end{array}$ & $\begin{array}{l}D C \\
(\%)\end{array}$ & $\begin{array}{l}D L \\
(\%)\end{array}$ & Referências \\
\hline Bison bison & \multirow{3}{*}{1} & 48,9 & 52,9 & 51,0 & $58,7 \mathrm{n}$ & 39,1 & 35,4 & & & & \multirow{3}{*}{$\begin{array}{c}\text { Galbraith et al. } \\
\text { (1998) }\end{array}$} \\
\hline Cervus elaphus & & 51,2 & 54,1 & 51,2 & $57,0 \mathrm{n}$ & 44,0 & 41,3 & & & & \\
\hline $\begin{array}{l}\text { Odocoileus } \\
\text { virginianus }\end{array}$ & & 46,9 & 49,1 & 46,4 & $56,6 n$ & 37,2 & 32,7 & & & & \\
\hline Cervus unicolor & 2 & 58,1 & 58,9 & & & 46,8 & & 56,7 & 52,4 & 7,4 & \multirow[t]{2}{*}{$\begin{array}{l}\text { Semiadi et al. } \\
\text { (1994) }\end{array}$} \\
\hline Cervus elaphus & & 59,6 & 60,9 & & & 50,0 & & 60,4 & 54,9 & 8,9 & \\
\hline Cervus elaphus & 3 & 75,2 & 80,6 & 76,6 & & 56,9 & 51,8 & 68,4 & 59,1 & 18,1 & $\begin{array}{l}\text { Hoskin et al. } \\
\text { (1995) }\end{array}$ \\
\hline $\begin{array}{l}\text { Odocoileus } \\
\text { hemionus }\end{array}$ & 4 & 56,4 & & & 69,7 & 47,9 & & & & & $\begin{array}{l}\text { Robbins } \\
\text { (1987) }\end{array}$ \\
\hline
\end{tabular}

Dietas: 1 - feno de alfafa peletizado 59,2\% FDN; 2 - feno de alfafa 50,1\% FDN; 3 - Chicorium intybus 23,8\% FDN; 4 - alfafa peletizada 48,7\% FDN.

DMS, digestibilidade da matéria seca; DMO, digestibilidade da matéria orgânica; DE, digestibilidade da energia; DPB, digestibilidade da proteína bruta; DFDN, digestibilidade da fibra em detergente neutro; DFDA, digestibilidade da fibra em detergente ácido; DH, digestibilidade da hemicelulose; DC, digestibilidade da celulose; DL, digestibilidade da lignina

Em relação ao extrato etéreo, Schneider \& Flatt (1975), exploraram alguns fatores que podem ter afetado os coeficientes de digestibilidade do presente estudo. Um destes fatores está relacionado aos baixos valores de extrato etéreo da dieta que pode ter contribuído para que o erro na determinação do coeficiente de digestão tenha sido relativamente grande. Outro fator que pode ter reduzido os coeficientes de digestibilidade do extrato etéreo está relacionado ao fato de que nas fezes existem 
frações de gordura, que escaparam da ação dos sucos digestivos, e que não são absorvidas, como os esteróis encontrados nas plantas e alguns materiais não lipídicos solúveis em éter, originários do alimento. Além disso, nas fezes pode-se encontrar frações lipídicas de origem metabólica, que podem ser interpretados como uma fração lipídica que não foi digerida nem absorvida provenientes do alimento. Deve-se ressaltar também que, com herbívoros, a digestão da gordura é limitada pela ação protecionista da celulose indigestível ao redor da gordura, que serve como uma barreira contra a ação digestiva.

Com relação ao FDN, os veados catingueiro apresentaram os menores coeficientes de digestibilidade, quando comparados a outros selecionadores de alimentos de fácil digestibilidade pesando menos de $20 \mathrm{~kg}$ como os "blue duikers", e os veados camundongo. O processamento do alimento pode ter influenciado os resultados obtidos neste estudo, pois os alimentos peletizados têm uma taxa de passagem mais rápida pelo trato digestivo em relação a alimentos com tamanho de partículas maiores (Mertens, 1993). Hironaka et al. (1996), observaram que a alfafa peletizada reduziu a digestibilidade da matéria seca em $11 \%$, quando a ingestão foi de 1,6 vezes a exigência de mantença. Outro fator que pode ter contribuído para a diminuição da digestibilidade dos constituintes da parede celular, está relacionado à redução das atividades fibrolíticas, geradas pela redução do $\mathrm{pH}$ ruminal, quando forragens trituradas são fornecidas aos animais. Esta redução do pH pode estar ligada a uma diminuição no tempo de mastigação e, como consequiência, uma redução na produção das substâncias tamponantes via saliva (Chesson et al., 1995). Já comparando os coeficientes de digestibilidade do FDN obtidos com os animais do presente estudo, com outras espécies de ruminantes pesando acima de $20 \mathrm{~kg}$, observoutse que, além da forma do alimento, outro fator que pode ter influenciado a digestibilidade poderia ter sido a maior taxa de passagem da dieta inerente aos veados catingueiro, em relação às outras espécies e, conseqüentemente, um curto tempo de exposição da dieta aos microrganismos do rúmen.

Segundo Oliveira \& Duarte (no prelo), comparando o tempo de trânsito intestinal em quatro diferentes espécies de cervídeos neotropicais (Mazama americana, Mazama gouazoubira, Mazama nana e Blastocerus dichotomus) recebendo quatro diferentes 
espécies de plantas, dentre elas a alfafa, observaram que os veados catingueiros (Mazama gouazoubira) apresentaram o menor tempo de trânsito no trato gastrointestinal em relação às outras espécies estudadas. Esta provável ineficiência dos veados catingueiro em relação à capacidade de digerir a fração fibra, corrobora as idéias de Hofmann (1973), sugerindo que estes pequenos ruminantes, são adaptados à selecionar alimentos com uma alta taxa de passagem como frutas e grãos, compensando sua baixa suplementação de energia vinda da produção de ácidos graxos voláteis no rúmen e, permitindo ainda que esses animais evitem as perdas de energia envolvidas na fermentação microbiana, pela produção de metano e calor. Mesmo apresentando coeficientes de digestibilidade de frações como FDN, hemicelulose e celulose menores em relação às outras espécies de ruminantes, estes valores podem ser suficientes para que esses pequenos frugívoros possam substituir parcialmente sua dieta, competir com outros herbívoros e sobreviver em uma ampla diversidade de ambientes. Segundo Bodmer (1989), isto ocorre em determinadas regiões da Amazônia, que se alagam periodicamente forçando os animais a consumirem maiores proporções de forragens devido a uma redução de seus habitats. Wenninger \& Shipley (2000) observaram que pequenos selecionadores de alimentos como os "blue duikers" supriram suas exigências nutricionais quando alimentados com folhas de salgueiro (Salix lasiandra) com $49 \%$ de FDN, ingerindo $50 \%$ a mais de matéria seca e ruminando 7 vezes mais do que quando eram alimentados com dietas de baixa fibra. Mesmo que os veados catingueiro, assim como outros pequenos ruminantes frugívoros, apresentem uma capacidade de digerir alimentos fibrosos, devido a sua pequena estatura e suas especializações morfológicas, podem apresentar limitações sobre a quantidade e o tipo de fibra que pode ser utilizada. Quando "blue duikers" foram alimentados com coastcross (Cynodon dactylon) com $72 \%$ de FDN e festuca (Festuca arundinacea) com 47\% de FDN, as partículas de alimentos escaparam pelo orifício retículo-omasal e foram retidas pelo piloro, causando a morte de um dos "blue duikers" de cada dieta (Luginbuhl et al., 1990).

Segundo Schoonveld et al. (1974), comparando a capacidade de digestão em veados mula, ovinos e caprinos recebendo uma dieta de alfafa com 56,1\% de FDN, observaram que seis dos oito cervídeos alimentados com alfafa peletizada e cinco dos 
oito alimentados com cubos de alfafa tiveram problemas digestivos. As necrópsias mostraram inflamações nos tecidos do omaso, abomaso e no baixo trato digestivo, assim como uma grande quantidade de partículas grande foi encontrada no omaso e abomaso dos cervídeos que apresentaram problemas digestivos, sugerindo que os alimentos passaram para fora do rúmen rapidamente sem uma digestão adequada. Segundo esses autores, as grandes partículas encontradas no omaso sugerem a falta de um mecanismo que regule o tamanho das partículas que são colocadas para fora do rúmen.

\subsection{Perfis e concentrações de n-alcanos}

Analisando os diferentes perfis e as concentrações dos n-alcanos nos diferentes ingredientes utilizados na formulação da dieta, observourse a ausência destes compostos nas amostras de levedura. Com relação às amostras de amido de milho, foram detectados $\mathrm{n}$-alcanos entre o $\mathrm{C}_{22}$ e $\mathrm{C}_{28}$. Porém, todos em pequenas concentrações sendo o $\mathrm{C}_{25}$ o mais abundante com 12,6 mg/kg de MS. Já o feno de alfafa, apresentou um perfil de $\mathrm{n}$ alcanos do $\mathrm{C}_{22}$ ao $\mathrm{C}_{33}$, sendo o $\mathrm{C}_{31}$ presente em maiores concentrações, seguido do $\mathrm{C}_{29} \mathrm{e}$ $\mathrm{C}_{27}$, respectivamente. Através da Tabela 7 pode-se visualizar as concentrações dos diferentes n-alcanos encontrados nos ingredientes citados acima. 
Tabela 7. Concentração dos n-alcanos (mg/kg MS) nos ingredientes utilizados na dieta

\begin{tabular}{ccccc}
\hline & Levedura & Amido de Milho & Feno de Alfafa & Dieta Peletizada \\
$\mathrm{C}_{22}$ & - & 6,7 & 18,1 & - \\
$\mathrm{C}_{23}$ & - & 10,2 & 29,4 & 3,5 \\
$\mathrm{C}_{24}$ & - & 12,5 & 33,8 & 4,4 \\
$\mathrm{C}_{25}$ & - & 12,6 & 44,9 & 8,1 \\
$\mathrm{C}_{26}$ & - & 11,5 & 34,8 & 5,1 \\
$\mathrm{C}_{27}$ & - & 8,7 & 61,9 & 16,8 \\
$\mathrm{C}_{28}$ & - & 6,8 & 30,3 & 8,9 \\
$\mathrm{C}_{29}$ & - & - & 154,5 & 59,9 \\
$\mathrm{C}_{30}$ & - & - & 25,4 & 10,4 \\
$\mathrm{C}_{31}$ & - & - & 481,8 & 226,6 \\
$\mathrm{C}_{32}$ & - & - & 18,5 & 9,9 \\
$\mathrm{C}_{33}$ & - & - & 36,1 & 31,4 \\
\hline n-alcan os de cadeia & & 37,5 & 160,9 & 38,7 \\
par & & & \\
n-alcanos de cadeia & & 31,5 & 808,6 & 336,3 \\
impar & & & 0,83 \\
n-alcanos de cadeia & & 0,45 & & \\
impar & & & & \\
(proporçôes do total) & &
\end{tabular}

Estudos pioneiros de Oró et al. (1965), mostraram que os cinco hidrocarbonetos mais comuns, entre as espécies de plantas são o $\mathrm{G}_{25}, \mathrm{C}_{27}, \mathrm{C}_{29}, \mathrm{C}_{31}$ e o $\mathrm{C}_{33}$. Tulloch (1976), observou que os hidrocarbonetos estão presentes em todas as ceras, sendo que os principais apresentam em sua cadeia números ímpares de carbono e se encontram entre os n-alcanos $\mathrm{C}_{21}$ a $\mathrm{C}_{37}$, sendo o $\mathrm{C}_{31}$ presente quase que regularmente em maiores concentrações seguido do $\mathrm{C}_{29}$.

Semelhante aos resultados encontrados no presente estudo, Gedir \& Hudson (2000), encontraram o $C_{31}$ como sendo o mais abundante n-alcano em cubos de alfafa, seguido pelo $\mathrm{C}_{29}$. Sendo que apenas traços do $\mathrm{C}_{35}$ puderam ser detectados.

Da mesma forma, estudando 6 diferentes espécies de plantas, Dove et al. (1996), observaram que o ralcano predominante nas leguminosas foi o $\mathrm{G}_{9}$ embora a alfafa também tenha apresentado altas concentrações do n-alcano $\mathrm{C}_{31}$ especialmente nos pecíolos e nas flores. Nas hastes de alfafa os nalcanos predominantes foram os $\mathrm{C}_{29}$ e o $\mathrm{C}_{31}$ assim como nas folhas e nos pecíolos, porém as concentrações destes n-alcanos diferenciaram marcantemente entre as frações das hastes. 
Segundo Dove \& Mayes (1991), em gramíneas, a relação entre os nalcanos $C_{29}$ e o $\mathrm{C}_{33}$ é baixa, apresentando altos níveis do nalcano $\mathrm{C}_{33}$. Já as leguminosas de clima temperado são marcadas pela alta relação entre os n-alcanos $C_{29}$ e $C_{33}$. De maneira similar, durante o presente estudo, pôde-se observar uma alta relação entre os n-alcanos $\mathrm{C}_{29}$ e $\mathrm{C}_{33}$, em virtude de um alto percentual de alfafa na dieta.

\subsection{Digestibilidade estimada através da utilização dos n-alcanos, e suas recuperações fecais}

Sabe-se que na alfafa apenas traços do n-alcano $\mathrm{C}_{35}$ são identificados, impossibilitando assim sua utilização como indicador. Do mesmo modo o nalcano $\mathrm{C}_{36}$ nesta espécie de leguminosa também se apresenta em pequenas concentrações (Gedir \& Hudson, 2000) e por isto, os cálculos das estimativas dos coeficientes de digestibilidade para a matéria seca, matéria orgânica, nitrogênio, extrato etéreo, energia e FDN, foram realizados utilizando apenas os n-alcanos $\mathrm{C}_{29}, \mathrm{C}_{31}$ e $\mathrm{C}_{33}$. Os coeficientes de digestibilidade estimados com o n-alcano $\mathrm{C}_{29}$ foram excluídos das análises estatísticas porque este indicador apresentou os menores valores de recuperação fecal. Nas Tabelas 8, 9 e 10 pode-se observar os valores de digestibilidade observados e estimados, através dos n-alcanos $\mathrm{C}_{29}, \mathrm{C}_{31}$ e $\mathrm{C}_{33}$, para os diferentes nutrientes. 
Tabela 8. Consumo, digestibilidade observada e estimada para matéria seca e matéria orgânica utilizando os n-alcanos $\mathrm{C}_{29}, \mathrm{C}_{31}$ e $\mathrm{C}_{33}$ em veados catingueiro ( $\mathrm{n}=8$ )

\begin{tabular}{|c|c|c|c|c|c|}
\hline \multicolumn{6}{|c|}{ Digestibilidade da matéria seca (DMS) } \\
\hline Animais & 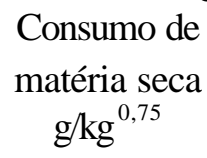 & $\begin{array}{r}\text { DMS \% } \\
\text { observada }\end{array}$ & $\begin{array}{c}\text { DMS \% } \\
\mathrm{C}_{29}\end{array}$ & $\begin{array}{c}\text { DMS \% } \\
\mathrm{C}_{31}\end{array}$ & $\begin{array}{c}\text { DMS \% } \\
\mathrm{C}_{33}\end{array}$ \\
\hline 1 & 42,8 & 60,6 & 47,2 & 48,5 & 52,9 \\
\hline 2 & 55,1 & 59,7 & 45,9 & 50,2 & 54,8 \\
\hline 3 & 44,3 & 60,4 & 51,9 & 55,0 & 58,6 \\
\hline 4 & 56,4 & 62,3 & 49,8 & 52,5 & 55,8 \\
\hline 5 & 46,1 & 61,6 & 47,6 & 53,6 & 56,9 \\
\hline 6 & 46,9 & 64,3 & 47,3 & 51,1 & 57,3 \\
\hline 7 & 49,1 & 63,6 & 48,3 & 54,8 & 57,2 \\
\hline 8 & 43,3 & 60,4 & 43,3 & 49,2 & 51,7 \\
\hline Média & 48,0 & 61,6 & 47,7 & 51,9 & 55,6 \\
\hline DP & $\pm 5,2$ & $\pm 1,7$ & $\pm 2,5$ & $\pm 2,5$ & $\pm 2,4$ \\
\hline
\end{tabular}

Digestibilidade da matéria orgânica (DMO)

Consumo de

\begin{tabular}{|c|c|c|c|c|c|}
\hline Animais & $\begin{array}{l}\text { matéria orgânica } \\
\qquad{\mathrm{g} / \mathrm{kg}^{0,75}}\end{array}$ & $\begin{array}{c}\text { DMO \% } \\
\text { observada }\end{array}$ & $\begin{array}{c}\mathrm{DMO} \% \\
\mathrm{C}_{29}\end{array}$ & $\begin{array}{c}\mathrm{DMO} \% \\
\mathrm{C}_{31}\end{array}$ & $\begin{array}{c}\mathrm{DMO} \% \\
\mathrm{C}_{33}\end{array}$ \\
\hline 1 & 38,9 & 62,6 & 49,9 & 51,2 & 55,2 \\
\hline 2 & 50,1 & 62,1 & 49,0 & 53,2 & 57,4 \\
\hline 3 & 40,2 & 63,1 & 55,1 & 58,0 & 61,2 \\
\hline 4 & 51,2 & 64,7 & 53,0 & 55,5 & 58,5 \\
\hline 5 & 41,9 & 63,8 & 50,6 & 56,3 & 59,3 \\
\hline 6 & 42,6 & 66,6 & 50,5 & 54,2 & 59,9 \\
\hline 7 & 44,6 & 65,6 & 51,0 & 57,2 & 59,4 \\
\hline 8 & 39,3 & 62,6 & 46,3 & 52,0 & 54,2 \\
\hline Média & 43,6 & 63,9 & 50,7 & 54,7 & 58,1 \\
\hline DP & $\pm 4,7$ & $\pm 1,6$ & $\pm 2,6$ & $\pm 2,5$ & $\pm 2,4$ \\
\hline
\end{tabular}


Tabela 9. Consumo, digestibilidade observada e estimada para o nitrogênio e o extrato etéreo utilizando os n-alcanos $\mathrm{C}_{29}, \mathrm{C}_{31}$ e $\mathrm{C}_{33}$ em veados catingueiro ( $\mathrm{n}=8$ )

\begin{tabular}{cccccc}
\hline \multicolumn{5}{c}{ Digestibilidade do nitrogênio (DN) } \\
Animais & $\begin{array}{c}\text { Consumo de } \\
\text { nitrogênio } \\
\mathrm{g} / \mathrm{kg}^{0,75}\end{array}$ & $\begin{array}{c}\mathrm{DN} \% \\
\text { observada }\end{array}$ & $\begin{array}{c}\mathrm{DN} \% \\
\mathrm{C}_{29}\end{array}$ & $\begin{array}{c}\mathrm{DN} \% \\
\mathrm{C}_{31}\end{array}$ & $\begin{array}{c}\mathrm{DN}_{33} \% \\
1\end{array}$ \\
& 1,3 & 69,0 & 59,1 & 60,2 & 63,4 \\
2 & 1,7 & 64,9 & 52,8 & 56,7 & 60,5 \\
3 & 1,4 & 71,9 & 65,8 & 68,1 & 70,5 \\
4 & 1,7 & 70,5 & 61,1 & 63,2 & 65,7 \\
5 & 1,4 & 67,7 & 56,0 & 61,1 & 63,7 \\
6 & 1,5 & 69,8 & 57,5 & 60,6 & 65,6 \\
7 & 1,5 & 76,1 & 66,6 & 70,8 & 72,3 \\
8 & 1,3 & 67,4 & 54,2 & 59,1 & 61,0 \\
\hline Média & 1,5 & 69,7 & 59,1 & 62,5 & 65,3 \\
DP & $\pm 0,2$ & $\pm 3,4$ & $\pm 5,1$ & $\pm 4,8$ & $\pm 4,2$ \\
\hline
\end{tabular}

Digestibilidade do extrato etéreo (DEE)

\begin{tabular}{cccccc} 
Animais & $\begin{array}{c}\text { Consumo de } \\
\text { extrato etéreo } \\
\mathrm{g} / \mathrm{kg}^{0,75}\end{array}$ & $\begin{array}{c}\mathrm{DEE} \% \\
\text { observada }\end{array}$ & $\begin{array}{c}\text { DEE } \% \\
\mathrm{C}_{29}\end{array}$ & $\begin{array}{c}\text { DEE \% } \\
\mathrm{C}_{31}\end{array}$ & $\begin{array}{c}\text { DEE \% } \\
\mathrm{C}_{33}\end{array}$ \\
1 & 0,5 & 37,6 & 16,3 & 18,5 & 25,2 \\
2 & 0,7 & 45,4 & 27,7 & 33,6 & 39,5 \\
3 & 0,5 & 42,9 & 27,8 & 32,5 & 37,7 \\
4 & 0,7 & 22,9 & $-0,5$ & 4,9 & 11,4 \\
5 & 0,6 & 33,1 & 8,2 & 18,7 & 24,3 \\
6 & 0,6 & 37,5 & 7,7 & 14,5 & 25,2 \\
7 & 0,6 & 39,4 & 13,8 & 24,6 & 28,5 \\
8 & 0,5 & 56,1 & 33,8 & 40,8 & 43,5 \\
\hline Média & 0,6 & 39,4 & 16,8 & 23,5 & 29,4 \\
DP & $\pm 0,1$ & $\pm 9,6$ & $\pm 11,9$ & $\pm 11,7$ & $\pm 10,4$ \\
\hline
\end{tabular}


Tabela 10. Consumo, digestibilidade observada e estimada para a energia e o FDN, utilizando os nalcanos $\mathrm{C}_{29}, \mathrm{C}_{31}$ e $\mathrm{C}_{33}$ em veados catingueiro ( $\left.\mathrm{n}=8\right)$

\begin{tabular}{cccccc}
\hline \multicolumn{5}{c}{ Digestibilidade da energia bruta (DEB) } \\
Animais & $\begin{array}{c}\text { Consumo de } \\
\text { energia bruta } \\
\mathrm{kcal} / \mathrm{kg}^{0,75}\end{array}$ & $\begin{array}{c}\text { DEB \% } \\
\text { observada }\end{array}$ & $\begin{array}{c}\text { DEB \% } \\
\mathrm{C}_{29}\end{array}$ & $\begin{array}{c}\text { DEB \% } \\
\mathrm{C}_{31}\end{array}$ & $\begin{array}{c}\text { DEB \% } \\
\mathrm{C}_{33}\end{array}$ \\
1 & 182,1 & 62,2 & 49,0 & 50,4 & 54,5 \\
2 & 234,5 & 61,1 & 47,5 & 51,8 & 56,1 \\
3 & 188,5 & 62,2 & 53,6 & 56,7 & 60,0 \\
4 & 240,0 & 63,4 & 51,1 & 53,7 & 56,9 \\
5 & 184,6 & 63,0 & 49,5 & 55,3 & 58,4 \\
6 & 199,5 & 65,4 & 48,7 & 52,4 & 58,4 \\
7 & 208,9 & 65,2 & 50,0 & 56,3 & 58,5 \\
8 & 184,0 & 61,4 & 44,2 & 50,1 & 52,4 \\
\hline Média & 202,8 & 63,0 & 49,2 & 53,3 & 56,9 \\
DP & $\pm 23,2$ & $\pm 1,6$ & $\pm 2,7$ & $\pm 2,6$ & $\pm 2,5$ \\
\hline
\end{tabular}

Digestibilidade da fibra em detergente neutro (DFDN) Consumo de

\begin{tabular}{cccccc} 
Animais & $\begin{array}{c}\text { FDN } \\
\mathrm{g} / \mathrm{kg}^{0,75}\end{array}$ & $\begin{array}{c}\text { DFDN \% } \\
\text { observada }\end{array}$ & $\begin{array}{c}\text { DFDN \% } \\
\mathrm{C}_{29}\end{array}$ & $\begin{array}{c}\text { DFDN \% } \\
\mathrm{C}_{31}\end{array}$ & $\begin{array}{c}\text { DFDN \% } \\
\mathrm{C}_{33}\end{array}$ \\
1 & 12,6 & 30,2 & 6,4 & 9,0 & 16,4 \\
2 & 16,3 & 30,3 & 6,1 & 13,8 & 21,5 \\
3 & 13,1 & 27,7 & 12,0 & 17,8 & 24,1 \\
4 & 16,6 & 33,8 & 11,8 & 16,5 & 22,2 \\
5 & 13,6 & 33,5 & 9,1 & 19,6 & 25,1 \\
6 & 13,8 & 38,6 & 9,4 & 16,0 & 26,6 \\
7 & 14,5 & 32,3 & 3,6 & 15,7 & 20,0 \\
8 & 12,8 & 27,3 & $-4,3$ & 6,7 & 11,0 \\
\hline Média & 14,2 & 31,7 & 6,8 & 14,4 & 20,9 \\
DP & $\pm 1,5$ & $\pm 3,7$ & $\pm 5,3$ & $\pm 4,4$ & $\pm 5,1$ \\
\hline
\end{tabular}


Através da utilização do n-alcano $C_{31}$, foi possível obter regressões significativas $(\mathrm{P}<0,01)$ entre os coeficientes de digestibilidade estimados e observados apenas para $\mathrm{o}$ nitrogênio, extrato etéreo e FDN. Já com o nalcano $\mathrm{C}_{33}$, além destes parâmetros a energia bruta também apresentou regressões significativas. Porém deve-se ressaltar que com o nalcano $\mathrm{C}_{33}$, apenas o nitrogênio e o extrato etéreo apresentaram níveis de significância a 1\%, sendo os demais significativos a 5\%. Observourse também durante o presente estudo, que nem todas as regressões significativas, apresentaram coeficientes de regressões iguais a 1, indicando que a técnica apresentou "viés", pois os valores estimados e observados não foram equivalentes.

Dove \& Coombe (1992) em um estudo realizado com ovinos em gaiolas metabólicas, observaram que os n-alcanos $\mathrm{C}_{31}$ e $\mathrm{C}_{33}$ utilizados como indicadores internos, permitiram estimar com precisão a digestibilidade da dieta. Na Tabela 11 estão descritas as equações de regressão que foram significativas entre os valores observados e os estimados com os n-alcanos $\mathrm{C}_{31}$ e $\mathrm{C}_{33}$ assim como se observa também se os coeficientes de regressões foram iguais ou diferentes de 1 .

Durante as análises de regressões, animais com recuperações fecais acima ou abaixo da média de recuperação fecal do grupo, foram identificados pelo SAS como “outliers", sendo estes valores excluídos das análises. O animal três apresentou a maior recuperação fecal do nalcano $C_{31}(87,9 \%)$ fugindo da média de recuperação dos outros animais e, como conseqüência, seus valores estimados de digestibilidade se aproximaram muito dos valores observados em relação à média do grupo. Já o animal seis, apresentou a menor recuperação fecal do n-alcano $\mathrm{C}_{31}(73,1 \%)$ e como consequiência seus valores estimados de digestibilidade se afastaram dos valores observados, em relação aos outros animais, com recuperações fecais intermediárias. Com o nalcano $\mathrm{C}_{33}$, o animal três, continuou apresentando o maior valor de recuperação fecal (95,5\%), já o animal oito, para este n-alcano foi o que apresentou o menor valor de recuperação fecal $(81,9 \%)$. Os valores de consumo, produção fecal e recuperação fecal, dos oito animais, podem ser observados na Tabela 12 .

Devido à incompleta recuperação fecal do $\mathrm{C}_{31}$ e do $\mathrm{C}_{33}$, apenas o extrato etéreo estimado com o n-alcano $\mathrm{C}_{33}$ foi significativo $(\mathrm{P}>0,05)$ diante o teste t para comparações 
de médias emparelhadas. Para todas as outras frações analisadas, os n-alcanos $C_{31}$ e $C_{33}$ subestimaram os coeficientes de digestibilidade em relação aos valores observados. Oliveira et al. (2000), utilizaram o nalcano $\mathrm{C}_{35}$ e observaram que os coeficientes de digestibilidade estimados com este indicador foram subestimados tanto para matéria seca, quanto para matéria orgânica apresentando uma diferença média em relação aos coeficientes de digestibilidade in vivo de -4,68 $(\neq 0,69)$ e $-4,43 \notin 0,85)(\mathrm{P}<0,01)$, respectivamente. Atribuindo esta diferença a uma recuperação média do $\mathrm{C}_{35}$ de 91,76\%. Piasentier et al. (1989) estudando a utilização dos nalcanos de cadeia ímpares entre o $\mathrm{C}_{27}$ ao $\mathrm{C}_{33}$, como indicadores internos, para estimar a digestibilidade, observaram que devido a uma recuperação fecal incompleta, estes indicadores também subestimaram os valores de digestibilidade obtidos através de ensaios in vivo, sendo o n-alcano $\mathrm{C}_{33}$ o que apresentou os maiores valores de recuperação fecal com média de 83,4\%.

Comparando a digestibilidade in vivo de cinco diferentes dietas, dentre elas um feno de alfafa, com a estimada pelo n-alcano $C_{31}$, Sandberg et al. (2000), observaram que para todas as dietas o n-alcano $\mathrm{C}_{31}$ subestimou $(\mathrm{P}<0,01)$ os coeficientes de digestibilidade, sendo a recuperação fecal deste indicador para o feno de alfafa, de $80,4 \%$. Fornecendo a ovinos uma dieta composta por azevém (Lolium multiflorum) e trevo branco (Trifolium repens) Mayes \& Lamb (1984), obtiveram valores superiores de recuperação fecal para os n-alcanos $\mathrm{C}_{31}$ e $\mathrm{C}_{33}$ em relação aos obtidos no presente estudo, sendo $83 \%$ e $90 \%$, respectivamente. 
Tabela 11. Equações de regressão entre os coeficientes de digestibilidade estimados com os n-alcanos $\mathrm{C}_{31}$ e $\mathrm{C}_{33}$ e os coeficientes de digestibilidade observados

\begin{tabular}{ccccccc}
\hline $\mathrm{Y}$ & $\mathrm{X}$ & $\mathrm{a}$ & $\mathrm{b}$ & $\mathrm{b}$ & $\mathrm{r}$ & $\mathrm{r}^{2}$ \\
\hline $\mathrm{CDN}$ (vivo) & $\mathrm{CDN} \mathrm{C}_{31}$ & 22,57 & 0,75 & $\mathrm{~b} \neq 1$ & 0,97 & 0,94 \\
$\mathrm{CDN}$ (vivo) & $\mathrm{CDN} \mathrm{C}_{33}$ & 13,48 & 0,86 & $\mathrm{~b}=1$ & 0,97 & 0,95 \\
$\mathrm{CDEE}$ (vivo) & $\mathrm{CDEE} \mathrm{C}_{31}$ & 18,85 & 0,83 & $\mathrm{~b}=1$ & 0,97 & 0,94 \\
$\mathrm{CDEE}$ (vivo) & $\mathrm{CDEE} \mathrm{C}_{33}$ & 16,23 & 0,75 & $\mathrm{~b} \neq 1$ & 0,96 & 0,93 \\
$\mathrm{CDEB}$ (vivo) & $\mathrm{CDEB} \mathrm{C}_{33}$ & 31,55 & 0,55 & $\mathrm{~b}=1$ & 0,75 & 0,57 \\
$\mathrm{CDFDN}$ (vivo) & $\mathrm{CDFDN} \mathrm{C}_{31}$ & 24,89 & 0,46 & $\mathrm{~b} \neq 1$ & 0,92 & 0,84 \\
$\mathrm{CDFDN}$ (vivo) & $\mathrm{CDFDN} \mathrm{C}_{33}$ & 22,69 & 0,44 & $\mathrm{~b} \neq 1$ & 0,89 & 0,79
\end{tabular}

CDN = Coeficiente de digestibilidade do nitrogênio

$\mathrm{CDEE}=$ Coeficiente de digestibilidade do extrato etéreo

$\mathrm{CDEB}=$ Coeficiente de digestibilidade da energia bruta

$\mathrm{CDFDN}=$ Coeficiente de digestibilidade da fibra em detergente neutro

Tabela 12. Consumo (g), produção fecal $(\mathrm{g})$ e recuperação fecal $(\%)$ dos nalcanos $\mathrm{C}_{29}$,

$\mathrm{C}_{31}$ e $\mathrm{C}_{33}$ com veados catingueiro

\begin{tabular}{cccccc}
\hline Animal & Consumo & $\begin{array}{c}\text { Produção } \\
\text { Fecal }\end{array}$ & $\begin{array}{c}\text { Recuperação } \\
\text { Fecal C } 29\end{array}$ & $\begin{array}{c}\text { Recuperação } \\
\text { Fecal C }_{31}\end{array}$ & $\begin{array}{c}\text { Recuperação } \\
\text { Fecal C } 33\end{array}$ \\
1 & 358,2 & 141,2 & 74,7 & 76,6 & 83,7 \\
2 & 516,8 & 208,0 & 74,3 & 80,9 & 89,0 \\
3 & 387,8 & 153,5 & 82,2 & 87,9 & 95,5 \\
4 & 456,1 & 171,9 & 75,0 & 79,3 & 85,3 \\
5 & 417,8 & 160,3 & 73,2 & 82,6 & 89,0 \\
6 & 417,7 & 149,2 & 67,8 & 73,1 & 83,7 \\
7 & 378,6 & 137,5 & 70,3 & 80,3 & 84,8 \\
8 & 323,3 & 127,9 & 69,7 & 77,9 & 81,9 \\
\hline Média & 407,0 & 156,2 & 73,4 & 79,8 & 86,6 \\
DP & $\pm 60,1$ & $\pm 25,0$ & $\pm 4,4$ & $\pm 4,4$ & $\pm 4,4$ \\
\hline
\end{tabular}


Quando se determina o coeficiente de digestibilidade de qualquer nutriente com um indicador, assume-se que a recuperação fecal é de $100 \%$. Porém, sabe-se que nenhum indicador é recuperado totalmente nas fezes. Em relação aos n-alcanos, Mayes et al. (1988), utilizando ovinos com cânulas intestinais, observaram que os n-alcanos, encontrados naturalmente nas forragens, apresentaram variações não significativas durante sua passagem pelo compartimento ruminal, sugerindo que a microflora do rúmen, não metabolizou os n-alcanos. Porém, um maior desaparecimento dos n-alcanos foi observado entre o duodeno e o íleo terminal sugerindo que a recuperação incompleta é devido a sua absorção no intestino. Como suporte a esse estudo, n-alcanos marcados com ${ }^{14} \mathrm{C}$, têm demonstrado que após o desaparecimento frente ao trato digestivo, aproximadamente 16 a $18 \%$ são encontrados no $\mathrm{CO}_{2}$ expirado (Kolattukudy \& Hankin, 1966).

Devido a essa recuperação fecal incompleta dos n-alcanos, os coeficientes de digestibilidade estimados com os nalcanos $\mathrm{C}_{31}$ e $\mathrm{C}_{33}$ durante o presente estudo foram ajustados, para um valor médio de recuperação fecal tanto para o $\mathrm{C}_{31}$, quanto para o $\mathrm{C}_{33}$. Este ajuste foi sugerido por Lucas (1952), onde a porcentagem de recuperação de um determinado indicador pode ser inserido na equação, como mostra o esquema abaixo:

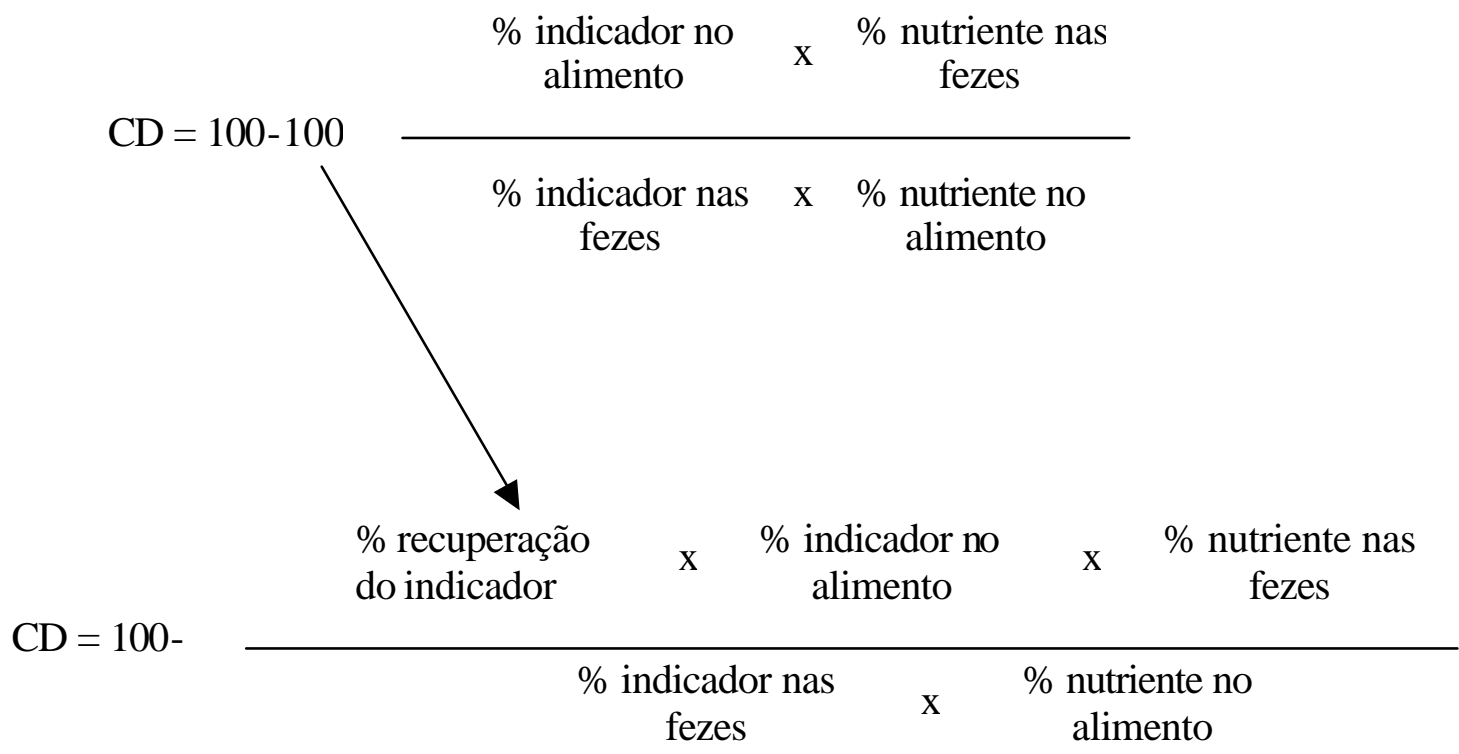


Este ajuste na equação fez com que os coeficientes de digestão estimados com os indicadores, $\mathrm{C}_{31}$ e $\mathrm{C}_{33}$, se tornassem acurados em relação aos coeficientes de digestão observados. Através do teste $\mathrm{t}$ para comparações de médias emparelhadas, os coeficientes de digestibilidade para todos os nutrientes, se tornaram significativos, ( $\mathrm{P}>0,05)$ após o ajuste para recuperação fecal. Através das Tabelas 13, 14 e 15, pode-se observar os coeficientes de digestibilidade ajustados com os n-alcanos $\mathrm{C}_{31}$ e $\mathrm{C}_{33}$. 
Tabela 13. Consumo, digestibilidade observada e estimada para matéria seca e matéria orgânica utilizando os n-alcanos $C_{31}$ e $C_{33}$ ajustados para recuperação fecal $(\mathrm{n}=8)$

\begin{tabular}{|c|c|c|c|c|}
\hline \multicolumn{5}{|c|}{ Digestibilidade da matéria seca (DMS) } \\
\hline Animais & $\begin{array}{l}\text { Consumo de } \\
\text { matéria seca } \\
{\mathrm{g} / \mathrm{kg}^{0,75}}\end{array}$ & $\begin{array}{c}\text { DMD \% } \\
\text { observada }\end{array}$ & $\begin{array}{c}\mathrm{DMD} \% \\
\mathrm{C}_{31}\end{array}$ & $\begin{array}{c}\mathrm{DMD} \% \\
\mathrm{C}_{33}\end{array}$ \\
\hline 1 & 42,8 & 60,6 & 58,9 & 59,2 \\
\hline 2 & 55,1 & 59,7 & 60,3 & 60,8 \\
\hline 3 & 44,3 & 60,4 & 64,1 & 64,1 \\
\hline 4 & 56,4 & 62,3 & 62,1 & 61,8 \\
\hline 5 & 46,1 & 61,6 & 62,9 & 62,7 \\
\hline 6 & 46,9 & 64,3 & 61,0 & 63,1 \\
\hline 7 & 49,1 & 63,6 & 63,9 & 62,9 \\
\hline 8 & 43,3 & 60,4 & 59,5 & 58,2 \\
\hline Média & 48,0 & 61,6 & 61,6 & 61,6 \\
\hline DP & $\pm 5,2$ & $\pm 1,7$ & $\pm 2,0$ & $\pm 2,0$ \\
\hline
\end{tabular}

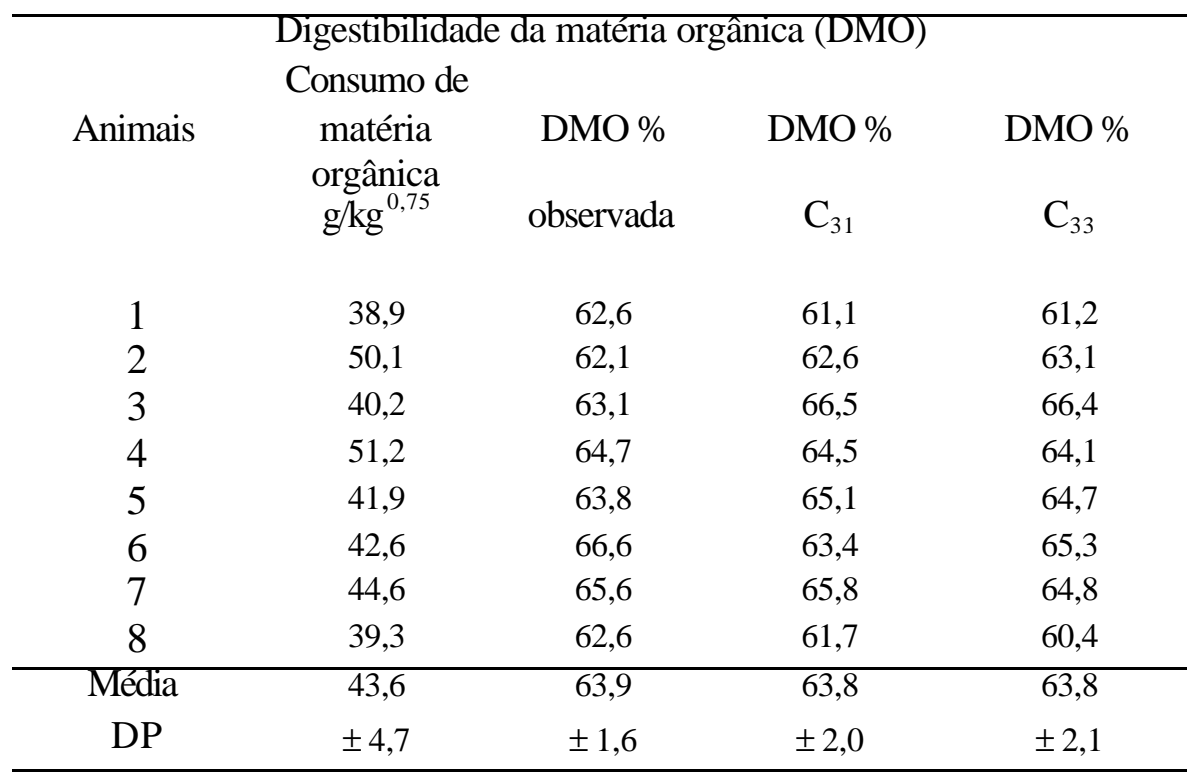


Tabela 14. Consumo, digestibilidade observada e estimada para o nitrogênio e o extrato etéreo utilizando os n-alcanos $\mathrm{C}_{31}$ e $\mathrm{C}_{33}$ ajustados para recuperação fecal $(\mathrm{n}=8)$

\begin{tabular}{ccccc}
\hline \multicolumn{5}{c}{ Digestibilidade do nitrogênio (DN) } \\
Animais & $\begin{array}{c}\text { Consumo de } \\
\text { nitrogênio } \\
\mathrm{g} / \mathrm{kg}^{0,75}\end{array}$ & $\begin{array}{c}\text { DN \% } \\
\text { observada }\end{array}$ & $\begin{array}{c}\text { DN \% } \\
\mathrm{C}_{31}\end{array}$ & $\begin{array}{c}\text { DN \% } \\
\mathrm{C}_{33}\end{array}$ \\
1 & 1,3 & 69,0 & 68,2 & 68,3 \\
2 & 1,7 & 64,9 & 65,4 & 65,8 \\
3 & 1,4 & 71,9 & 74,5 & 74,5 \\
4 & 1,7 & 70,5 & 70,6 & 70,3 \\
5 & 1,4 & 67,7 & 68,9 & 68,6 \\
6 & 1,5 & 69,8 & 68,6 & 70,2 \\
7 & 1,5 & 76,1 & 76,7 & 76,0 \\
8 & 1,3 & 67,4 & 67,3 & 66,2 \\
\hline Média & 1,5 & 69,7 & 70,0 & 70,0 \\
DP & $\pm 0,2$ & $\pm 3,4$ & $\pm 3,8$ & $\pm 3,7$ \\
\hline
\end{tabular}

\begin{tabular}{|c|c|c|c|c|}
\hline \multicolumn{5}{|c|}{ Digestibilidade do extrato etéreo (DEE) } \\
\hline Animais & $\begin{array}{c}\text { Consumo de } \\
\text { extrato etéreo } \\
\mathrm{g} / \mathrm{kg}^{0,75}\end{array}$ & $\begin{array}{c}\text { DEE \% } \\
\text { observada }\end{array}$ & $\begin{array}{c}\text { DEE \% } \\
C_{31}\end{array}$ & $\begin{array}{c}\text { DEE \% } \\
\mathrm{C}_{33}\end{array}$ \\
\hline 1 & 0,5 & 37,6 & 35,0 & 35,2 \\
\hline 2 & 0,7 & 45,4 & 47,0 & 47,6 \\
\hline 3 & 0,5 & 42,9 & 46,1 & 46,0 \\
\hline 4 & 0,7 & 22,9 & 24,1 & 23,3 \\
\hline 5 & 0,6 & 33,1 & 35,2 & 34,5 \\
\hline 6 & 0,6 & 37,5 & 31,8 & 35,3 \\
\hline 7 & 0,6 & 39,4 & 39,9 & 38,1 \\
\hline 8 & 0,5 & 56,1 & 52,7 & 51,1 \\
\hline Média & 0,6 & 39,4 & 39,0 & 38,9 \\
\hline DP & $\pm 0,1$ & $\pm 9,6$ & $\pm 9,3$ & $\pm 9,0$ \\
\hline
\end{tabular}


Tabela 15. Consumo, digestibilidade observada e estimada para a energia e o FDN, utilizando os n-alcanos $\mathrm{C}_{31}$ e $\mathrm{C}_{33}$ ajustados para recuperação fecal (n=8)

\begin{tabular}{|c|c|c|c|c|}
\hline \multicolumn{5}{|c|}{ Digestibilidade da energia bruta (DEB) } \\
\hline Animais & $\begin{array}{l}\text { Consumo de } \\
\text { energia bruta } \\
\mathrm{kcal} / \mathrm{kg}^{0,75}\end{array}$ & $\begin{array}{c}\text { DEB \% } \\
\text { observada }\end{array}$ & $\begin{array}{c}\mathrm{DEB} \% \\
\mathrm{C}_{31}\end{array}$ & $\begin{array}{c}\text { DEB \% } \\
\mathrm{C}_{33}\end{array}$ \\
\hline 1 & 182,1 & 62,2 & 60,4 & 60,6 \\
\hline 2 & 234,5 & 61,1 & 61,6 & 62,0 \\
\hline 3 & 188,5 & 62,2 & 65,4 & 65,3 \\
\hline 4 & 240,0 & 63,4 & 63,1 & 62,7 \\
\hline 5 & 184,6 & 63,0 & 64,3 & 63,9 \\
\hline 6 & 199,5 & 65,4 & 62,1 & 64,0 \\
\hline 7 & 208,9 & 65,2 & 65,1 & 64,1 \\
\hline 8 & 184,0 & 61,4 & 60,1 & 58,8 \\
\hline Média & 202,8 & 63,0 & 62,8 & 62,7 \\
\hline $\mathrm{DP}$ & $\pm 23,2$ & $\pm 1,6$ & $\pm 2,0$ & $\pm 2,2$ \\
\hline
\end{tabular}

\begin{tabular}{|c|c|c|c|c|}
\hline \multicolumn{5}{|c|}{ Digestibilidade da fibra em detergente neutro (DFDN) } \\
\hline \multirow{3}{*}{ Animais } & onsumo c & & & \\
\hline & FDN & DFDN \% & DFDN \% & DFDN \% \\
\hline & $\mathrm{g} / \mathrm{kg}^{0,75}$ & observada & $\mathrm{C}_{31}$ & $\mathrm{C}_{33}$ \\
\hline 1 & 12,6 & 30,2 & 27,3 & 27,6 \\
\hline 2 & 16,3 & 30,3 & 31,2 & 32,0 \\
\hline 3 & 13,1 & 27,7 & 34,4 & 34,3 \\
\hline 4 & 16,6 & 33,8 & 33,4 & 32,6 \\
\hline 5 & 13,6 & 33,5 & 35,8 & 35,1 \\
\hline 6 & 13,8 & 38,6 & 33,0 & 36,4 \\
\hline 7 & 14,5 & 32,3 & 32,7 & 30,8 \\
\hline 8 & 12,8 & 27,3 & 25,6 & 23,0 \\
\hline Média & 14,2 & 31,7 & 31,7 & 31,5 \\
\hline DP & $\pm 1,5$ & $\pm 3,7$ & $\pm 3,5$ & $\pm 4,4$ \\
\hline
\end{tabular}


Comparando a digestibilidade da matéria seca in vivo com as estimadas pelos $\mathrm{A}$ alcanos $\mathrm{C}_{32}, \mathrm{C}_{33}$ e $\mathrm{C}_{36}$ em vacas de leite recebendo diferentes dietas, Unal \& Garnsworthy (1999), encontraram resultados congruentes entre os valores observados e estimados com os diferentes nalcanos, sendo os valores de ecuperação fecal dos nalcanos utilizados como fatores de correção nas estimativas de digestibilidade.

A recuperação fecal dos n-alcanos durante este estudo aumentou com o aumento do comprimento da cadeia de carbono, sendo os resultados similares aos obtidos por Mayes \& Lamb (1984), Mayes et al. (1988) e Dove et al. (1989) e, podem ser observados nas Figuras 7 e 8 . Os valores médios de recuperação fecal do $C_{27}, C_{28}, C_{29}, C_{30}, C_{31}, C_{32}$ e $C_{33}$ foram $73,7 \%, 83,5 \%, 73,4 \%, 80,2 \%, 79,8 \%, 86,6 \%$ e $86,6 \%$, respectivamente, e poderão ser utilizados em futuros estudos onde a composição botânica deseja ser determinada.

Em primeiro instante, estas médias de recuperação fecal serão utilizadas em outro trabalho que vêm sendo desenvolvido paralelamente, cujo objetivo é determinar a demanda e aporte de energia em cervídeos brasileiros através do método da água duplamente marcada e de n-alcanos. Com estes valores de recuperação fecal, os pesquisadores pretendem determinar a composição botânica em nível de espécie ou grupos de plantas consumidas pelos veados campeiro em seu habitat utilizando equações simultâneas (Dove, 1991). 


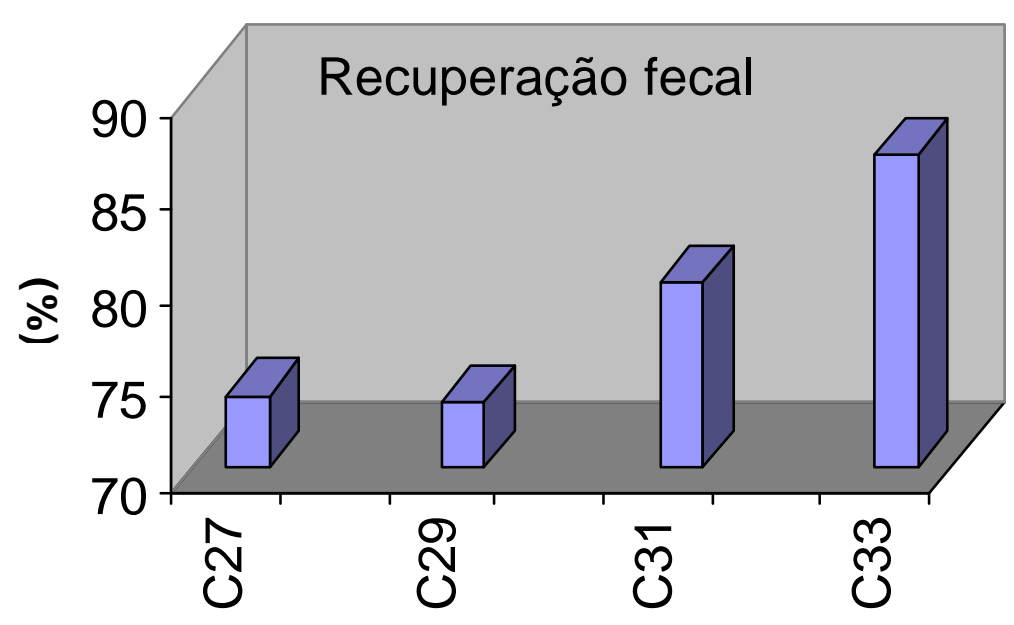

n-alcanos

Figura 7 - Recuperações fecais dos n-alcanos de cadeia ímpares

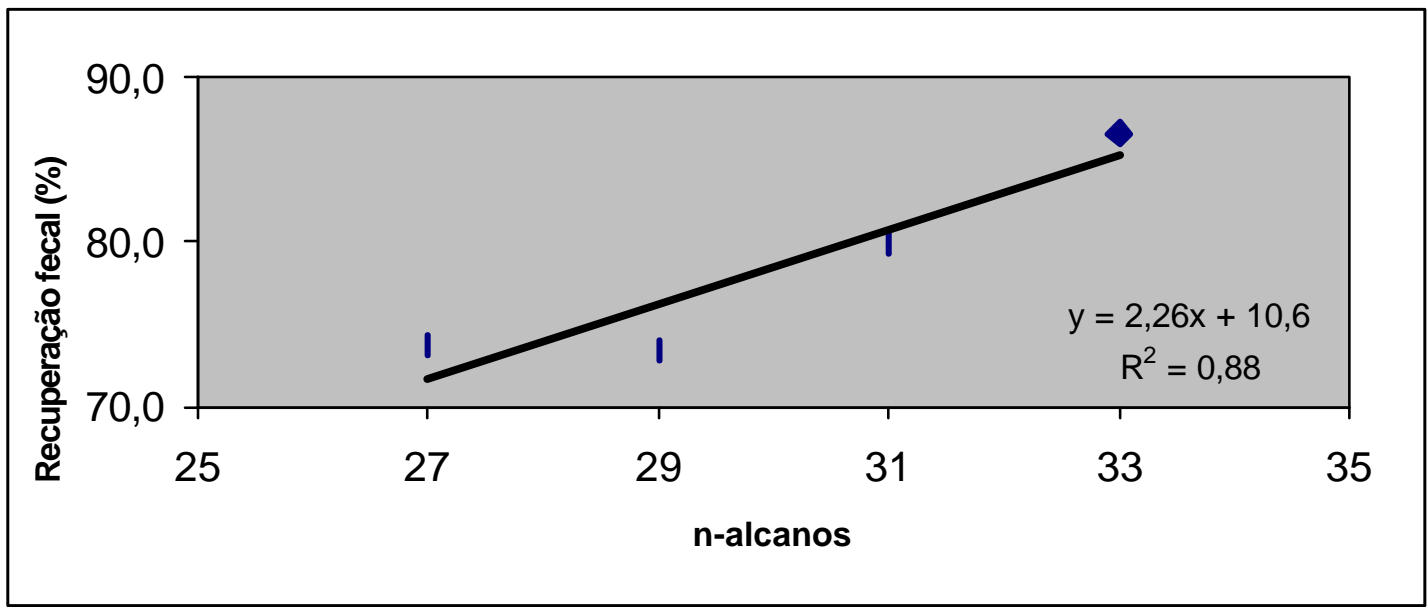

Figura 8 - Regressão linear entre os ntalcanos de cadeia ímpares, e as médias de suas recuperações fecais em 8 veados catingueiros (Mazama gouazoubira) 


\section{CONCLUSÕES}

Os resultados de consumo e digestibilidade obtidos pelo método de coleta total foram pioneiros e podem ser utilizados como importante ferramenta na manutenção dessa espécie em seus habitats.

O emprego e a validação da técnica dos ralcanos foram uma alternativa não invasiva e eficiente na determinação da digestibilidade em veados catingueiro.

Quando ajustados para um valor médio de recuperação fecal, os coeficientes de digestibilidade estimados com os n-alcanos mostraram se precisos e acurados.

As médias de recuperação fecal dos diferentes n-alcanos, obtidas neste trabalho, podem ser utilizadas em futuros estudos onde se queira estimar a composição botânica consumida por cervídeos em cativeiro ou em seus habitats. 


\section{REFERÊNCIAS BIBLIOGRÁFICAS}

BARBERÍA, F.J.P.; GORDON, I.J.; ILLIUS, A.W. Philogenetic analysis of stomach adaptation in digestive strategies in African ruminants. Oecologia, v.129, p.498$508,2001$.

BODMER, R.E. Frugivory in amazonian artiodactyla: evidence for the evolution of the ruminant stomach. Journal Zoology, v.219, p.457-467, 1989.

BODMER, R.E. Responses of ungulates to seasonal inundations in the amazon floodplain. Journal of Tropical Ecology, v.6, p.191-201, 1990.

CHESSON, A.; FORSBERG, C.W.; GRENET, E. Improving the digestion of plant cell walls and fibrous feed. In:Recent developments in the nutrition of herbivores, In: INTERNATIONAL SYMPOSIUM ON THE NUTRITION OF HERBIVORES, 5, Paris, 1995. Proceedings. Paris, 1995. p.249-277.

CHURCH, D.C. The Ruminant Animal, Digestive Physiology and Nutrition Illinois: Waveland Press,1993. 564p.

CLAUSS, M.; LECHNER-DOLL, M.; FLACH, E.J.; TACK, C.; HATT, J.M. Comparative use of four different marker systems for the estimation of digestibility and low food intake in a group of captive giraffes (Giraffa camelopardalis). Zoo Biology, v. 20, p.315-329, 2001. 
CONKLIN, N.L.; DIERENFELD, E.S. Digestibility and passage of standard zoo diet fed to greater mouse deer (Tragulus napu) Malaysian Natural Journal, v.48, p. 41-51, 1994.

CONKLIN-BRITTAIN, N.L.; DIERENFELD, E.S. Small Ruminarts: Digestive capacity differences among four species weighing less than $20 \mathrm{~kg}$. Zoo Biology, v.15, p.481-490, 1996.

COOK, A.H. The chemistry and biology of yeasts. New York: Academic Press, 1958. $763 p$.

CORK, S.J. Digestive constraints on dietary scope in small and moderately-small mammals: how much do we really understand? In: CHIVERS, D.J; LANGER P. (Ed.). The digestive system in mammals: food, form, and function. Cambridge: Cambridge University Press, 1994. p.370-390.

DEBBRECHT, F.J. Qualitative and quantitative analysis by gas chromatography. In: GROB, R. L. (Ed.) Modern practice of gas chromatography. 2.ed. New York: Wiley Interscience, 1985. p. 359-421.

DILLON, P.; STAKELUM, G. The analysis of n-alkanes in faeces and herbage. In: EUROPEAN GRAZING WORKSHOP, 7. Wageningen, 1990. Proceedings. Wageninger: Ed Institute voor Veevoedingsoderzoek, 1990a. 1v.

DOVE, H.; MAYES, R.W. The use of plant wax alkanes as marker substances in studies of the nutrition of herbivores: A Review. Australian Jo urnal Agricultural Research. v.42, p.913-952, 1991. 
DOVE, H.; COOMBE, J.B. A comparison of methods for estimating supplement intake and diet digestibility in sheep. Proceedings of the Australian Society of Animal Production, v. 19, p. 239-241, 1992.

DOVE, H.; FOOT, J.Z.; FREER, M. Estimation of pasture intake in grazing ewes, using the alkanes of plant cuticular waxes. In: INTERNATIONAL GRASSLAND CONGRESS, 16, Nice, 1989. Proceedings. Nice: French Academy of Science, 1989. p.1091-1092.

DOVE, H.; MAYES, R.W.; FREER, M. Effects of species, plant part, and plant age on the n-alkane concentrations in the cuticular wax of pasture plants. Australian Journal Agricultural Research, v.47, p.1333-1347, 1996.

DUARTE, J.M.B. Biologia e Conservação de Cervídeos Sul-Americanos: Blastocerus, Ozotoceros e Mazama. Jaboticabal: FUNEP, 1997. 238p.

EISEMBERG, J.E. The evolutionary history of the Cervidae with special reference to the south american radiation. In: WEMMER, C.M. (Ed.) Cap 6. Biology and Management of the Cervidae. Washington: Smithsonian Institution Press, 1984. p.60-64.

GALBRAITH, J.K.; MATHISON, G.W.; HUDSON, R.J.; McALLISTER, T.A.; CHENG, K.-J. Intake, digestibility, methane and heat production in bison, wapiti and white-tailed deer. Canadian Journal of Animal Science, v.97, n.3, p.681-691, 1998.

GEDIR, J.V.; HUDSON, R.J. Estimating dry matter digestibility and intake in wapiti (Cervus elaphus canadensis) using the double n-alkane ratio technique. Small Ruminant Research v.36, p. 57-62, 2000. 
GOERING, H.K.; VAN SOEST, P.J. Forage fiber analyses (apparatus, reagents, procedures and some applications).Washington, D.C: US Government Printing Office, 1970. p. 140-147. (USDA-ARS Agricultural Handbook, 379)

GORDON, I.J.; ILLIUS, A.W. The functional significance of the browser-grazer dichotomy in African ruminants. Oecologia, v.98, p.167-175, 1994.

HAMMOND, K.A.; WUNDER, B.A. The role of diet quality and energy need in the nutritional ecology of a small herbivore, Microtus ochrogaster. Physiology Zoology, v.64, p.541-567, 1991.

HATT, J.M.; DOLL, M.L.; MAYES, B. The use of dosed and herbage ralkanes as markers for the determination of digestive strategies of captive giraffes. Zoo Biology, v.17, p.295-309, 1998.

HAWKE, J.C., In: BUTLER, G.W., BAILEY, R.W. (Ed.). v.1 Chemistry and biochemistry of herbage, London: Academic Press, 1973. p.213-263.

HIRONAKA, R.; MATHISON, G.W.; KERRIGAN, B.K.; VLACH, I. The effect of pelleting of alfalfa hay on methane production and digestibility by steers. Science Total Environmental, v.180, p.221-227, 1996.

HOFMANN, R.R. The ruminant stomach (stomach structure and feeding habits of east african game ruminants)., E.A. Lit Bureau, Nairobi: East African Biology, 1973. v.2 p.1-364.

HOFMANN, R.R. Morphophysiological evolutionary adaptations of the ruminant digestive system. In: DOBSON, A (Ed.). Comparative aspects of physiology of digestion in ruminants. Ithaca: Cornell University Press, 1988. p.1-20. 
HOFMANN, R.R. Evolutionary steps of ecophysiological adaptation and diversification of ruminants: a comparative view of their digestive system. Oecologia, v.78, p.443457, 1989.

HOLTER, J.B.; URBAN, W.E. Water partitioning and intake prediction in dry and lactating holstein cows. Journal of Dairy Science, v. 75, p.1472-1479, 1992.

HOSKIN, S.O.; STAFFORD, K.J.; BARRY, T.N. Digestion, rumen fermentation and chewing behaviour of red deer fed fresh chicory and perennial ryegrass. Journal of Agricultural Science, v.124, p.289-295, 1995.

HOWSE, A.J.; SEMIADI, G.; STAFFORD, K.J.; BARRY, T.N.; MUIR, P.D. Digestion and chewing behaviour of young sambar and red deer consuming a low quality roughage. Journal of Agricultural Science, v.125, p.399-405, 1995.

HULBERT, I.A.R.; IASON, G.R.; MAYES, R.W. The flexibility of na intermediate feeder: dietary selection by mountain hares measured using faecal n-alkanes. Oecologia, v. 129, p. 197-205, 2001.

HUSTON, J.E.; RECTOR, B.S.; ELLIS, W.C.; ALLEN, M.L. Dynamics of digestion in cattle, sheep, goats and deer. Journal Animal Science, v.62, p.208-215, 1986.

KOLATTUKUDY, P.E.; HANKIN, L. Metabolism of a plant wax paraffin (nnonacosane) in the rat. Journal Nutrition, v.90, p.167-174, 1966.

LUCAS, H.L. Methods of computing results of grazing trials. Journal Animal Science, v.11, p.784, 1952. 
LUGINBUHL, J.M.; POND, K.R.; BURNS, J.C. Physical limits to ruminal escape: experiences with the blue duiker. Symposium on digestive strategies of animals, National Zoological Park, Smithsonian Institution, Washington, DC. 1990.

MAYES, R.W.; LAMB, C.S. The possible use of n-alkanes in herbage as indigestible faecal markers. Proceedings of Nutrition Society, v.43, n.13, p.39, 1984.

MAYES, R.W.; LAMB, C.S.; COLGROVE, P.M. The use of dosed and herbage $n$ alkanes as markers for the determination of herbage intake. Journal of Agricultural Science, v.107, n.1, p.161-170, 1986.

MAYES, R.W.; LAMB, C.S.; COLGROVE, P.M. Digestion and metabolism of dosed even-chain and odd-chain ralkanes in sheep. In: GEN. MEET. EUR. GRASSL. FED., 12, Dublin. 1988. Proceedings. Dublin: p.159-163.

MAYES, R.W., IASON, G.R., WHITE, N.; PALO,T. Measuring diet composition and food intake by moose in the Swedish boreal forest: integration of GPS and faecal marker technologies. Proceedings: of GPS Conference, Tracking Animals with GPS of A.M. Sibbald and I.J Gordon (Eds). Macaulay Land Use Research Instiute, Aberdeen, p. 77-80, 2001.

MAYNARD, L.A. LOOSLI, J.K. Animal nutrition 6.ed. New York: McGraw-Hill Book Company, 1969. 613p.

Mc NAIR, A.J.; BONNELLI, K. Basic Chromatography. 4.ed. Palo Alto: Varian Instrument Division Offices, 1968. 167p.

MERTENS, D.R. Kinetics of cell wall digestion and passage in ruminants. ASA, Madison, WI: ASA, 1993. P. 535-570: Forage cell wall struture and digestibility. 
NOLAN, J.V.; LIANG, J.B.; ABDULLAH, N.; KUDO, H.; ISMAIL, H.; HO, Y.W.; JALALUDIN, S. Food intake, nutrient utilization and water turnover in the lesser mouse-deer (Tragulus javanicus) given lundai (Sapium baccatum). Compendium Biochemical Physiology, v.111, p.177-182, 1995.

NORBURY, G.L., SANSON, G.D. Problems with measuring diet selection of terrestrial, mammalian herbivores. Australian Journal Ecology. v.17, p. 1-7, 1992.

OLIVEIRA, L.D.; DUARTE, J.M.B. Tempo de trânsito gastro-intestinal em cervídeos sul americanos e suas implicações ecológicas e evolutivas. In: CONGRESSO BRASILEIRO DE MASTOZOOLOGIA, 2., Belo Horizonte, Resumo. p. 281-282. 2003.

OLIVEIRA, D.E.; PRATES, E.R.; PERALBA, M.C.R. Identificação e quantificação de n-alcanos presentes nas ceras de plantas forrageiras. Revista Brasileira de Zootecnia, v.26, n.5, p.881-886, Set.Out.1997.

OLIVEIRA, D.E.; ETCHEGARAY, M.A.; LANNA, D.P.D. Plastic syringes as a substitute to disposable columns in the extraction of the nalkanes used in nutritional studies with herbivores. (compact disc). In: REUNIÃO ANUAL DA SOCIEDADE BRASILEIRA DE ZOOTECNIA, 39.; Recife, 2002, Anais. Recife: SBZ, 2002.

ORÓ, J.; NOONER, D.W.; WIKSTRON, S.A. Paraffinic hydrocarbons in pasture plants. Science, v. 47, n.3659, p.870-873, 1965.

OWEN-SMITH, N. Grazers and browsers: ecological and social contrasts among African ruminants. In: SPITZ F.; JANEAU G.; GONZALEZ G.; AULAGNIER S. (Ed.). Toulouse: SFEPM-IRGM, 1991. p.175-181.(Ongules, Ungulates, 91.). 
PARKER, K.L.; ROBBINS, C.T. Thermoregulation in mule deer and elk. Canadian Journal Zoology, v.62, p.1409-1422, 1984.

PIASENTIER, E.; PISON, S.; BOVOLENTA, S. Impiego degli n-alcani negli studi sulla digeribilitá in vivo dei foraggi. Zootechny Nutrition Animal, v.15, p.691-696, 1989.

RAMANZIN, M.; BAILONI, L.; SCHIAVON, S. Effect of forage to concentrate ratio on comparative digestion in sheep, goats and fallow deer. Animal Science, v.64, p.163-170, 1997.

ROBBINS, C.T.; SPALINGER, D.E.; VAN HOVEN, W. Adaptation of ruminants to browse and grass diets: are anatomical-based browser-grazer interpretation valid? Oecologia, v.103, p.208-213, 1995.

ROSE, A.H.; HARRISON, J.S. The yeasts. London: Academic Press, 1970. 470p.

SANDBERG, R.E.; ADAMS, D.C.; KLOPFENSTEIN, T.J.; GRANT, R.J. N-alkane as an internal marker for predicting digestibility of forages. Journal Range Management, v.53, p.159-163, 2000.

SANTOS, E. Entre o Gambá e o Macaco. 5.ed. Belo Horizonte: Itatiaia, 1984.

SAS INSTITUTE. SAS/SAT: User's guide. Cary, 1999. 1v.

SCHNEIDER, B.H.; FLATT, W.P. The evaluation of feeds through digestibility experiments. Athens: University of Georgia Press, 1975, 423p.

SCHOONVELD, G.G.; NAGY, J.G.; BAILEY, J.A. Capability of mule deer to utilize fibrous alfalfa diets. Journal Wildlife Management, v.38, p.823-829, 1974. 
SEMIADI, G.; BARRY, T.N.; STAFFORD, K.J.; MUIR, P.D.; REID, C.S.W. Comparison of digestive and chewing efficiency and time spent eating and ruminating in sambar deer (Cervus unicolor) and red deer (Cervus elaphus). Journal of Agricultural Science, v.123, p.89-97, 1994.

SHORT, H.L. Nutrition of southern deer in different seasons. Journal Wildlife Management, v.39, p.321-329, 1975.

TAYLOR, C.R.; LYMAN, C.P. A comparative study of the environmental physiology of an East African antelope, the eland, and the Hereford steer. Physiology Zoology, v.40, p.280-295, 1967.

TULLOCH, A.P. Chemistry and Biochemistry of Natural Waxes. New York: Elsevier, 1976. p.235-287.

TULLOCH, A.P. Composition of epicuticular waxes from 28 genera of Graminae: differences between subfamilies. Canadian Journal Botanical, v.59, p.1213-1221, 1981.

TULLOCH, A.P.; BAUM, B.R.; HOFFMAN, L.L. A survey of epicuticular waxes among genera of Triticeae. Canadian Journal Botanical, v. 58, p. 2602-2615, 1980.

UNAL, Y.; GARNSWORTHY, P.C. Estimation of intake and digestibility of foragebased diets in group-fed dairy cows using alkanes as markers. Journal of Agricultural Science, v.133, p.419-425, 1999.

UNTZ, G. Manuel Pratique de Chromatographie en Phase Gazeuse. 3.ed. Paris: Masson, 1982. p.61-72. 
VAN SOEST,P.J. Nutritional ecology of the ruminant. 2.ed. New York: Cornell University, 1994. 476p.

VAN SOEST, P.J.; ROBERTSON, J.B.; LEWIS, B.A. Methods for dietary fiber, neutral detergent fiber, and non-starch polysaccharides in relation to animal nutrition. Journal Dairy Science, v.74, p.3583-3597, 1991.

WALKER, E. Mammals of the world. Baltimore: John Hopkins University Press, 1991. 1398p.

WENNINGER, P.S.; SHIPLEY, L.A. Harvesting, rumination, digestion, and passage of fruit and leaf diets by a small ruminant, the blue duiker. Oecologia, v.123, p.466474, 2000. 